\title{
Enhancing rhamnolipid production and exploring the mechanisms of low-foaming fermentation under weak-acid conditions
}

\section{Zhijin Gong}

Qufu Normal University

Ge Yang

Qufu Normal University

Chengchuan Che

Qufu Normal University

Jinfeng Liu

Qufu Normal University

Meiru Si

Qufu Normal University

Qiuhong He ( $\nabla$ hqiuhong228@163.com )

Qufu Normal University https://orcid.org/0000-0003-0513-7615

\section{Research}

Keywords: Rhamnolipid fermentation, Pseudomonas aeruginosa, weak-acid conditions, mutagenesis, zeta potential, morphology

Posted Date: June 12th, 2020

DOl: https://doi.org/10.21203/rs.3.rs-34693/v1

License: (9) This work is licensed under a Creative Commons Attribution 4.0 International License.

Read Full License 


\section{Abstract}

The commercialized applications of rhamnolipid has seriously impeded by high cost of production caused by severe foaming. Effective low-foaming fermentation and mechanism study have become the most urgent requirement for larger-scale production of rhamnolipid. In this study, the low-foaming fermentation was realized by controlling fermentation at $\mathrm{pH}$ 5.5. Further, the production of rhamnolipid was enhanced 0.9-fold by the ultraviolet and ethyl methanesulfonate composite mutagenesis. To the best of our knowledge, this was the first report to enhance production of rhamnolipid by strain improvement at weak-acid conditions. The mechanisms exploration tests indicated that increasing surface tension and decreasing viscosity were conducive to reduce foaming ability of rhamnolipid fermentation. The decrease of negatively charged ions may weaken the electrostatic repulsion between charged substances adsorbed membranes of bubbles such as rhamnolipid and cells, leading to the liquid membranes to rupture easily. In addition, the structure of vesicle or lamellar of rhamnolipid formed at pH5.0-6.0 may also weaken the foaming ability of rhamnolipid fermentation. The work revealed the promising potentiality for genetic modification to enhance the production of rhamnolipid and facilitated the understanding of $\mathrm{pH}$-associated foaming behavior, as well as were conducive to develop a more effective $\mathrm{pH}$-associated control strategies for large-scale production of rhamnolipid.

\section{Background}

Rhamnolipid with excellent properties such as biodegradability, low toxicity, antimicrobial, good surface activity and emulsification [1, 2] and usually produced by Pseudomonas aeruginosa [3], was currently the most potential biosurfactant to apply in oil recycling $[4,5]$ and environmental protection [6], food processing $[7,8]$ and biomedical industry $[9,10]$. However, despite their potential, the industrial application of rhamnolipid was restricted seriously since the cost of rhamnolipid production was approximate ten times that of synthetic surfactant [11]. One of the major reasons was due to the severe foaming in fermentation [12-14]. Although a large quantity of fermentation strategies, including anaerobic $[15,16]$ and solid fermentation $[14,17,18]$ have attempted to solve the severe foaming, submerged liquid fermentation still seems to be the sole approach for the high-yield production of rhamnolipid at present [19]. Therefore, to reduce foaming behavior in submerged liquid fermentation of rhamnolipid have become an urgent requirement for the large-scale production and application of rhamnolipid [13]. In this respect, some fermentation strategies such as fermentation-defoaming tandem system, foam fractionation fermentation $[20,21]$ and foam adsorption fermentation $[22,23]$ have been carried out, but all of these fermentation strategies were ex-situ and caused some problems such as loss of culture fluid, high contamination risk and increasing cost of equipment. Recently, the in-situ lowfoaming fermentation with maximal rhamnolipid production was realized by controlling fermentation at pH5.5-5.7. This improved a promising strategy to efficiently product rhamnolipid by the conventional submerged liquid fermentation without equipment transformation [24].

However, according to previous studies, the most of rhamnolipid fermentation by controlling $\mathrm{pH}$ at $\mathrm{pH} 5.0$ 6.0 were unsatisfactory, because the cell growth and rhamnolipid synthesis were also conspicuously 
inhibited $[11,25]$. Therefore, in this study, we first evaluated the potentiality of low-foaming rhamnolipid fermentation of Pseudomonas aeruginosa SW1 at weak-acid conditions by detecting foaming behavior and production ability. Further, the production ability of $P$. aeruginosa SW1 was enhanced by ultraviolet (UV) and ethyl methanesulfonate (EMS) composite mutagenesis at pH5.5. Finally, the mechanisms of low-foaming fermentation of rhamnolipid caused by weak-acid conditions were also systematically explored by characterizing effects of $\mathrm{pH}$ on viscosity, surface tension, zeta potential, foaming behavior and morphological change of rhamnolipid fermentation.

\section{Materials And Methods}

\section{Bacterial strain and medium}

A Pseudomonas aeruginosa SW1 stored in our laboratory was first grown in nutrient broth at $37^{\circ} \mathrm{C}$ and $200 \mathrm{rpm}$ in an orbital shaker until the optical density at $600 \mathrm{~nm}$ reached approximately 2.0. The broth culture then was used as the fermentation inoculum. The medium of fermentation contained: $40 \mathrm{~g} / \mathrm{L}$ soybean oil; $5 \mathrm{~g} / \mathrm{l} \mathrm{NaNO}{ }_{3} ; 1.1 \mathrm{~g} / \mathrm{l} \mathrm{KCl} ; 1.1 \mathrm{~g} / \mathrm{l} \mathrm{NaCl} ; 4 \mathrm{~g} / \mathrm{I} \mathrm{KH}_{2} \mathrm{PO}_{4} ; 4.4 \mathrm{~g} / \mathrm{I} \mathrm{K}_{2} \mathrm{HPO}_{4}$; and $0.5 \mathrm{~g} / \mathrm{l}$ $\mathrm{MgSO}_{4} \cdot 7 \mathrm{H}_{2} \mathrm{O}$. The medium was sterilized at $121^{\circ} \mathrm{C}$ for $20 \mathrm{~min}$ for fermentation. Chemicals were purchased from Sinopharm Chemical Reagent Co., Ltd. The bean oil was purchased from Shandong Luhua group Industry Co., Ltd (Laiyang, China).

\section{Fermentation}

The seed culture was inoculated at 1:10 into medium of fermentation. In $250 \mathrm{ml}$ Erlenmeyer flasks, fermentation was conducted at $37^{\circ} \mathrm{C}$ with orbital shaking at $200 \mathrm{rpm}$ for $96 \mathrm{~h}$. In the fermenter, a $7.5 \mathrm{I}$ fermenter produced by Shanghai Baoxing Bio-Engineering Co, Ltd. (Shanghai, China) with 4 I working volume was employed to the fermentation. Four different fermentation strategies were used as described in Fig. 6. The temperature of fermentation was maintained at $37^{\circ} \mathrm{C}$. The $\mathrm{pH}$ was controlled by addition of $3 \mathrm{M} \mathrm{HCl}$ or ammonia. Agitation was fixed at $300 \mathrm{rpm} / \mathrm{min}$ and aeration flux was set to $3 \mathrm{~L} / \mathrm{min}$.

\section{Rhamnolipid Concentration And Biomass}

The production of rhamnolipid in the fermentation broth were quantified by the colorimetric determination of sugars moiety with orcinol [14]. The culture broth of rhamnolipid was initially centrifuged (10 $000 \mathrm{~g}$, $10 \mathrm{~min}$ ) to separate the cells from the supernatant. $0.5 \mathrm{ml}$ of supernatant was extracted thrice using $1 \mathrm{ml}$ of chloroform/ethanol $(2: 1, \mathrm{v} / \mathrm{v})$. The organic phase was collected and evaporated to dryness, the rhamnolipid residue was then dissolved in deionized water. Approximately $2.7 \mathrm{ml}$ of a solution containing $0.19 \%$ orcinol (in $53 \% \mathrm{H}_{2} \mathrm{SO}_{4}$ ) was then added to $0.3 \mathrm{ml}$ of each sample. After heating for $30 \mathrm{~min}$ at $80{ }^{\circ} \mathrm{C}$, the samples were cooled in an ice-water bath for $2 \mathrm{~min}$, and the samples' absorbance at $421 \mathrm{~nm}$ was measured. Rhamnolipid were quantified in triplicate and rhamnolipid concentration was calculated by 
multiplying the amount of rhamnose by 3.4 [26]. The dry weight method was employed to measure biomass. Error bars in the figure were standard deviations from triplicate experiments.

\section{Rhamnolipid Purification}

The rhamnolipid purification was performed according to wang's method with minor modification [27]. Briefly, the culture medium was centrifuged at $10000 \mathrm{rpm}$ at $4{ }^{\circ} \mathrm{C}$ for $10 \mathrm{~min}$. The supernatant was precipitated by acidifying culture supernatant to $\mathrm{pH} 2.0$ with $6 \mathrm{M}$ hydrochloric solution and kept at $4{ }^{\circ} \mathrm{C}$ overnight, then recovered by centrifugation at $10,000 \mathrm{rpm}$ at $4{ }^{\circ} \mathrm{C}$ for $1 \mathrm{~h}$ and dissolved in deionized water. Two volumes of chloroform:ethanol (2:1, v/v) were added to rhamnolipid solution and shaken $1 \mathrm{~h}$ for extraction at room temperature. The organic phase was evaporated to dryness to remove the solvent at $40^{\circ} \mathrm{C}$. After solvent evaporation, the rhamnolipid residue was obtained.

\section{Foaming Properties}

The fermentation broth of rhamnolipid $(22 \mathrm{~g} / \mathrm{l}, 30 \mathrm{ml})$ from $250 \mathrm{ml}$ Elenmeyer flask were controlled at $\mathrm{pH} 4, \mathrm{pH} 5, \mathrm{pH} 6, \mathrm{pH} 7$ and $\mathrm{pH} 8$ by $3 \mathrm{M} \mathrm{HCl}$ and ammonia. Among them, the $\mathrm{pH} 7$ and $\mathrm{pH} 8$ were control groups for neutral $\mathrm{pH}$ and weak alkaline $\mathrm{pH}$, respectively. Then they were whipped with a rotor-stator disperser (AM400W-H, Angni Instruments Ltd, Shanghai, China) at $1000 \mathrm{rpm}$ for $2 \mathrm{~min}$ at $37^{\circ} \mathrm{C}$, after whipping, the foam was poured into a $100 \mathrm{~mL}$ graduated cylinder immediately. Foaming ability (FA) was determined by comparing the foam volume at $1 \mathrm{~min}$ to the initial liquid volume of samples. The foam volume of fermentation broth of rhamnolipid at 5 min was measured to evaluate the accumulation ability of foam.

\section{$\mathrm{FA}(\%)=\mathrm{V}_{0} / 30 \times 100(1)$}

where $V_{0}$ is the foam volume at $1 \mathrm{~min}$.

\section{Foaming microstructure observation by optical microscopy}

According to the method by Xiong's report [28] with slight modification, the microstructures of foams from fermentation broth of rhamnolipid at $\mathrm{pH} 4-8$ were visualized using a microscope (CX43, Olympus). The samples $(10 \mu \mathrm{L})$ were placed on microscopy glass slides. Foams were observed after being stored at $37^{\circ} \mathrm{C}$ for 1 and $5 \mathrm{~min}$. The magnification was 10 (objective) $\times 10$ (eyepiece).

\section{Composite mutagenesis by UV and EMS.}

For UV mutagenesis, the collected cells (3000 r/min for10min) were resuspended in nutrient broth at approximately $1 \times 10^{4}$ cells $\mathrm{mL}^{-1}$. Then the cells were exposed to UV for $5,10,20,30,40$, and $50 \mathrm{~s}$ using a 
$30 \mathrm{~W}$ lamp (245 nm, Shengxing ZW30S19W) at a distance of $30 \mathrm{~cm}$. The irradiated cells suspension was diluted 100 -fold with sterilized saline, and then $0.1 \mathrm{~mL}$ of dilution was spread on the blue agar plates [29] (the nutrient broth agar plates added $0.2 \mathrm{~g}$ cetyltrimethylammonium bromide (CTAB) and $0.005 \mathrm{~g}$ methylene blue, the value of $\mathrm{pH}$ was adjusted to 5.5 with $3 \mathrm{M} \mathrm{HCl}$ and $1 \mathrm{M} \mathrm{NaOH}$ ). The plates were incubated at $37^{\circ} \mathrm{C}$ for 5 days. All these manipulations were conducted in darkness to avoid possible photoreactivation. Strains with large blue circle were isolated for the further EMS mutagenesis. For EMS mutagenesis, the collected cells $(10000 \mathrm{r} / \mathrm{min}$ for $5 \mathrm{~min}$ ) were resuspended in sterilized saline at approximately $1 \times 10^{6}$ cells $\mathrm{ml}^{-1}$. Cells were subject to $5 \mathrm{ml} 2 \%(\mathrm{v} / \mathrm{v})$ EMS over $0.5 \mathrm{~h}$ in a dark room and then EMS was inactivated by addition of sterile sodium thiosulfate to a final concentration of $5 \%$. Cells were pelleted at $10000 \mathrm{r} / \mathrm{min}$ and washed three times with sterilized saline and resuspended in nutrient broth at approximately $1 \times 10^{6}$ cells $\mathrm{ml}^{-1}$. The cells suspension of $0.1 \mathrm{ml}$ was spread on the blue agar plates and were incubated at $37^{\circ} \mathrm{C}$ for 5 days.

\section{Surface tension, viscosities and zeta potential}

The fermentation broth of rhamnolipid from $7.5 \mathrm{I}$ fermenter was adjusted to $\mathrm{pH} 4-7$ by utilizing $3 \mathrm{M} \mathrm{HCl}$ and ammonia. The surface tensions were measured by the Wilhelmy plate method [30], using a tensiometer (SFZL-E, Innuo Pecision Instruments Ltd, Shanghai, China). The Wilhelmy plate was immersed in $20 \mathrm{ml}$ of aqueous phase at $37^{\circ} \mathrm{C}$. The viscosities were measured with a viscometer (NDJ-9S, Pingxuan Scientific Instrument CO., Ltd. Shanghai, China) operating in $60 \mathrm{rpm}$. The zeta potentials were measured using a Zetasizer Nano ZSP (Malvern Instruments Ltd, Malvern, UK).

\section{Rhamnolipid morphology}

The morphologies of rhamnolipid residue were observed with transmission electron microscopy (TEM). A drop of the test rhamnolipid solution sample was placed onto a copper grid and dried naturally 邓then was stained 2 min with a $1 \%$ phosphomolybdic acid aqueous solution. The excess phosphomolybdic acid aqueous solution was removed by absorbing the drop with a piece of filter paper and the grid was dried naturally. The samples were imaged under a transmission electron microscope (JEM-2100Plus, JEOL).

\section{Results And Discussion}

\section{Evaluation of foaming properties in pH4-8}

As shown in Fig. 1A, the FAs of fermentation broth at $\mathrm{pH} 4, \mathrm{pH} 5, \mathrm{pH} 6, \mathrm{pH} 7$ and $\mathrm{pH} 8$ were $32 \%, 41 \%, 42 \%$, $146 \%$ and $174 \%$, respectively (the corresponding visual foam volume image at Fig. $1 \mathrm{C}$ ). After being stored for $5 \mathrm{~min}$, there are less accumulation of foam at pH4, pH5 and pH6 (Fig. 1B). These indicated that the foaming behavior of fermentation broth of rhamnolipid could be obviously suppressed at at $\mathrm{pH} 4, \mathrm{pH} 5$ and pH6. The time evolutions of bubbles formed by fermentation broth of rhamnolipid were shown in 
Fig. 2. The fermentation broth of rhamnolipid at pH4-6 exhibited lesser multiple bubbles layers and smaller size of bubble at 1 min, which indicated that the fermentation broth of rhamnolipid at pH4-6 had a poor foaming ability. A main property of aqueous foams is that there is out-of-equilibrium systems, and they evolve in time by gravitational drainage, coarsening and film rupture [31]. In response to gravity the liquid flows out of the foam and this process is called drainage [32]. Drainage reduce the liquid fraction in the foam and increase film surface area of the bubbles, and cause an easier gas diffusion between bubbles. In foam, bubbles grow because of the gas diffusion from one bubble to the next and the coalescence of bubbles when films are breaking. Foams coarsen because of pressure differences between bubbles of different sizes [28]. These also result in an increase in the mean bubble size. The bubbles growth eventually cause film rupture. From the Fig. 2, after being stored for $5 \mathrm{~min}$, a lot of bubbles have ruptured and only a few small sizes bubbles existed in the field of vision at pH4-6, but the fermentation broth of rhamnolipid at pH7-8 still have more multiple bubbles layers and bigger size of bubble. These suggested that the ability of bubbles to prevent drainage or coarsening at $\mathrm{pH} 7-8$ was stronger than these at $\mathrm{pH} 4-6$ and the foam was easy to accumulate. The results of time evolution of air bubbles also provided a better understanding for high foaming behavior of fermentation of rhamnolipid.

Based on the above results, the foaming behavior of fermentation broth of rhamnolipid was typically $\mathrm{pH}$ dependency and could be conspicuously suppressed by weak-acid conditions.

\section{Fermentation Of Rhamnolipid At Ph5.5 And Ph6.0}

Owing to the metabolic activities of the microorganism, the $\mathrm{pH}$ value of fermentation of rhamnolipid by Pseudomonas aeruginosa would be increased from weak acid to weak alkaline (in this study, the value $\mathrm{pH}$ of was increased from 6.6 to 8.2, Fig. S1) [2, 33]. Base on above results, the foaming behavior may be enhanced at alkaline environment caused by metabolic of microorganism. Therefore, in order to reduce the foaming behavior of fermentation of rhamnolipid, the fermentation was firstly conducted at pH5.5. As shown in Fig. 3A, the fermentation exhibited a low-foaming behavior and could be conducted for $120 \mathrm{~h}$ or longer, which was conspicuously longer than the fermentation time of no control pH in Fig. S1. In addition, although the concentration of rhamnolipid and biomass increased along the entire fermentation, the maximum rhamnolipid concentration $(8.1 \mathrm{~g} / \mathrm{l})$ and biomass $(6.5 \mathrm{~g} / \mathrm{l})$ were obviously lower than the production of Erlenmeyer flask fermentation $(22 \mathrm{~g} / \mathrm{l}$ and $12.9 \mathrm{~g} / \mathrm{l}, \mathrm{Fig}$. S1). These results suggested that the foaming behavior of rhamnolipid fermentation was poor at pH5.5, meanwhile rhamnolipid synthesis and cell growth were also inhibited.

To improve the production of rhamnolipid, the $\mathrm{pH}$ of fermentation was adjusted to 6.0. Anti-foam agent was added at $1 \mathrm{ml} / \mathrm{l}$ broth at 60,72 and $86 \mathrm{~h}$ of the fermentation. The production of rhamnolipid and biomass were plotted in Fig. 3B. It was observed that the increase of $\mathrm{pH}$ could promote cell growth and rhamnolipid synthesis. The maximum production of rhamnolipid $(12.5 \mathrm{~g} / \mathrm{l})$ and biomass $(8.7 \mathrm{~g} / \mathrm{l})$ were 1.5-fold and 1.3-fold of pH5.5, respectively. However, severe foam occurred during fermentation (Fig. 3B) and a small amount of foam was overflowed. Given that overflowed cultivation was unacceptable in 
fermentation [34]. Therefore, the further fermentation of rhamnolipid was conducted at pH5.5. In addition, the results of fermentation at $\mathrm{pH} 5.5$ and $\mathrm{pH} 6.0$ also indicated that the foaming behavior of rhamnolipid fermentation was typical $\mathrm{pH}$-sensitive and 0.5 change of $\mathrm{pH}$ value would cause a conspicuous decline of foaming ability.

\section{Improved The Production Of Rhamnolipid By Mutagenesis At Ph5.5}

In order to improve the production of rhamnolipid, the $P$. aeruginosa SW1 was mutated by UV and EMS and screened by the blue agar plates. For UV mutagenesis, the strain mutated by UV was cultured on blue agar plates. The rhamnolipid produced by the colony of strain could form blue circle around the colony [29]. The blue circle diameter/colony diameter (BC) was proportional to the rhamnolipid concentration produced by strain. To obtain the mutant strains with increased production of rhamnolipid, 20 colonies with large blue circles were screened and the values of $B C$ were calculated. As shown in Table 1, all the mutant strains showed higher values of $\mathrm{BC}$ compared with control strain 0 . Strain 3 showed the highest value of $\mathrm{BC}$ with $16 \mathrm{~mm}$ blue circle diameters and $7 \mathrm{~mm}$ colony diameters. Strain 8 and strain 15 also showed significant enhanced production capacity with the high values of BC. Therefore, strain 3 , strain 8 and strain 15 were isolated for the EMS mutagenesis. For EMS mutagenesis, strain 3, strain 8 and strain 15 were mutated separately according to the method abovementioned in "Mutagenesis". Once again, 20 colonies with large blue circles were screened and the values of $B C$ were calculated. As shown in Table 1, strain 7 showed the highest value of $B C$ followed by strain 18 , strain 15 , strain 19 and strain 8 , which indicated that the rhamnolipid production may have a significant increase by mutagenesis in these strains. Therefore, strain 7 , strain 8 , strain 15 , strain 18 and strain 19 were isolated for the further studies. 
Table 1

$B C$ values of strains in culture plate after UV and EMS composite mutagenesis

\begin{tabular}{|c|c|c|c|c|c|c|c|}
\hline & UV & & & & EMS & & \\
\hline Code & $\mathrm{R} 1(\mathrm{~mm})$ & $\mathrm{R} 2(\mathrm{~mm})$ & $\mathrm{BC}$ & Code & $\mathrm{R} 1(\mathrm{~mm})$ & $\mathrm{R} 2$ (mm) & $\mathrm{BC}$ \\
\hline 0 & 6.0 & 4.0 & 1.5 & & & & \\
\hline 1 & 10.0 & 6.5 & 1.5 & 1 & 14.5 & 7.0 & 2.1 \\
\hline 2 & 9.5 & 5.0 & 1.9 & 2 & 19.0 & 7.5 & 2.5 \\
\hline 3 & 16.0 & 7.0 & 2.3 & 3 & 15.0 & 6.0 & 2.5 \\
\hline 4 & 7.5 & 4.0 & 1.9 & 4 & 19.0 & 9.0 & 2.1 \\
\hline 5 & 9.0 & 5.0 & 1.8 & 5 & 15.5 & 7.0 & 2.2 \\
\hline 6 & 16.5 & 9.0 & 1.8 & 6 & 14.0 & 6.5 & 2.2 \\
\hline 7 & 9.5 & 5.5 & 1.7 & 7 & 21.0 & 7.0 & 3.0 \\
\hline 8 & 13.0 & 6.0 & 2.2 & 8 & 16.0 & 6.0 & 2.7 \\
\hline 9 & 8.5 & 5.0 & 1.7 & 9 & 17.0 & 7.0 & 2.4 \\
\hline 10 & 8.0 & 4.5 & 1.8 & 10 & 15.0 & 6.0 & 2.5 \\
\hline 11 & 9.0 & 5.5 & 1.6 & 11 & 18.0 & 7.5 & 2.4 \\
\hline 12 & 11.5 & 6.5 & 1.8 & 12 & 17.0 & 6.5 & 2.6 \\
\hline 13 & 8.0 & 5.0 & 1.6 & 13 & 19.0 & 7.5 & 2.5 \\
\hline 14 & 12.5 & 6.0 & 2.1 & 14 & 18.0 & 8.0 & 2.3 \\
\hline 15 & 14.5 & 6.5 & 2.2 & 15 & 18 & 6.5 & 2.8 \\
\hline 16 & 14.5 & 8.5 & 1.7 & 16 & 19.0 & 7.5 & 2.5 \\
\hline 17 & 9.5 & 5.0 & 1.9 & 17 & 17.0 & 6.5 & 2.6 \\
\hline 18 & 13.0 & 7.5 & 1.7 & 18 & 20.0 & 7.0 & 2.9 \\
\hline 19 & 9.0 & 5.0 & 1.8 & 19 & 17.0 & 6.0 & 2.8 \\
\hline 20 & 13.0 & 7.5 & 1.7 & 20 & 18.0 & 7.0 & 2.6 \\
\hline
\end{tabular}

The high production performance of strains obtained by mutagenesis may be instability because of the mutation reversion often occurring during subculture [35]. To evaluate the stability of production, strain 7 , strain 8 , strain 15 , strain 18 and strain 19 were inoculated at a $7.5 \mathrm{I}$ fermenter with $2 \mathrm{I}$ initial fermentation 
medium respectively. After that, 1 I of fermentation liquid was removed and simultaneously 1 I of fresh fermentation medium was added by timer control digital pump every $48 \mathrm{~h}$ for continuous subculture. The pH5.5 was controlled by addition of $3 \mathrm{M} \mathrm{HCl}$ or ammonia. Agitation was fixed at $300 \mathrm{rpm} / \mathrm{min}$ and aeration flux was set to $2 \mathrm{l} / \mathrm{min}$. The productions of rhamnolipid were detected at 240, 288 and $336 \mathrm{~h}$, respectively. As shown in Fig. S2, after $336 \mathrm{~h}$ of continuous subculture, all the 5 strains showed excellent stability of production and the production of rhamnolipid were more than $11 \mathrm{~g} / \mathrm{L}$. The strain 7 still showed the highest productions of rhamnolipid $(13.6 \mathrm{~g} / \mathrm{L})$ followed by strain $15(12.9 \mathrm{~g} / \mathrm{L})$ and strain 18 $(12 \mathrm{~g} / \mathrm{L})$.

Further, the strain 7 and strain 15 were conducted to the fermentation according to the method of fermentation involved in "materrials and method". As shown in Fig. 2, after $120 \mathrm{~h}$ of fermentation, the production of rhamnolipid and biomass of strain 7 reached $15.4 \mathrm{~g} / \mathrm{l}$ and $10.3 \mathrm{~g} / \mathrm{L}$, which were 1.9-fold and 1.6-fold of the original strain, respectively. Corresponding, the production of rhamnolipid $(14.7 \mathrm{~g} / \mathrm{l})$ and biomass $(10.1 \mathrm{~g} / \mathrm{l})$ of strain 15 were about 1.8 -fold and 1.6 -fold of the original strain. The fermentation still exhibited low-foaming behavior in whole process of fermentation. These results indicated that enhancing the production of rhamnolipid at weak acid condition by mutagenesis was a promising strategy to realize low-foaming fermentation of rhamnolipid. In addition, other methods for strain improvement like metabolic engineering and synthetic biology techniques $[36,37]$ should be included in future studies for improving the productivity of rhamnolipid at weak-acid conditions and addressing the foaming problem of rhamnolipid fermentation.

\section{Characterizing the effects of pH5-6 on foaming of rhamnolipid fermentation}

According to these results abovementioned that fermentation at pH5.5 was a suitable strategy to realize low-foaming production of rhamnolipid by $P$. aeruginosa SW1. In addition, according to the previous reports, the pH5-6 were also considered to be suitable range to carry out the low-foaming fermentation of rhamnolipid [11, 25, 34]. Therefore, in order to explore the mechanism of low-foaming fermentation of rhamnolipid caused by weak acid $\mathrm{pH}$, we used a weak-alkaline condition $(\mathrm{pH} 8)$ as the control group to systematically evaluate the effects of fermentation broths and rhamnolipid residue on foaming behavior at pH5.0, pH5.5, and pH6.0.

\section{Effects Of Ph5-6 On Viscosity And Surface Tension}

Generally speaking, the foaming ability of solution is related to its surface tension and film viscosity [34]. The formation of bubbles is the process of increasing film surface area, and the increase in film surface area means that the energy of the system of bubbles also is increased correspondingly [38]. Therefore, from a thermodynamic point of view, the high surface tension of fermentation broth is obviously not conducive to foaming, because high surface tension will increase the surface energy of bubbles and 
producing the same volume of foam do more work. In addition, the liquid film of bubbles formed by low viscosity solution have low viscosity and strength $[39,40]$, which are also conducive to coalescence and accelerate the film rupture of bubbles. Therefore, according to the Fig. 5A and Fig. 5B, in comparison to that at $\mathrm{pH}$, the fermentation broth of rhamnolipid at pH5-6 exhibited lower viscosity and higher surface tension, which were conducive to suppress the severe foaming in the fermentation of rhamnolipid.

\section{Effects of pH5-6 on zeta potential and foaming behavior of rhamnolipid}

The foaming ability (Fig. 5C) and zeta potential (Fig. 5D) of solution of rhamnolipid residue were simultaneously reduced with the decline of $\mathrm{pH}$. Specially, there were obvious molecules aggregation of rhamnolipids and less foam at pH5.0 (Fig. S3). Given that the trend of the change of foaming behavior was accordance with the zeta potential, it was considered that the decrease of foaming could be also partly attributed to the decline in charge potential of rhamnolipid. Because rhamnolipid containing carboxyl group has negatively charge and smaller fractions of rhamnolipid would be present as negatively charged ions in aqueous solution $[41,42]$. The decrease of negatively charged ions would weaken the electrostatic repulsion between rhamnolipid and made the rhamnolipid molecules easy to aggregate and further impeded the foaming ability $[11,43]$. On the other hand, the decrease of negatively charged ions would also weaken the electrostatic repulsion of the charged cells adsorbed inner and outer membranes of bubbles and made the liquid membrane easy to drain, thin and rupture [44].

\section{Effects Of Ph5-6 On Morphology Of Rhamnolipid}

According to previous studies, the pKa of rhamnolipid reported was about 4.3-5.6, so rhamnolipid molecules may present vesicles and/or lamellar structures while at pH5.5 [45, 46]. To verify the structure of rhamnolipid at pH5-6, TEM was used to examine the morphology of the rhamnolipid microstructure. Figure 6 clearly shown the conversion of molecular aggregates of rhamnolipid was typical pH-sensitive. The vesicles structure predominated at pH5.0, while the larger lamellar were presented at pH5.5. This was consistent with obvious molecules aggregation of rhamnolipid shown in pH5.0 (Fig. S3). The size of lamellar significant became small at pH6.0, but no lamellar or vesicles was observed at pH8.0. Compared with the foaming behavior of rhamnolipid presented in Fig. 5C, it may be that formation of such vesicles or lamellar structures significantly suppressed the foaming ability of rhamnolipid.

In condition, according to the previous findings, there are a paradox that rhamnolipid has been characterized as having low foam ability, but its fermentation presented severely foaming $[47,48]$. The reason may be that the $\mathrm{pH}$ of rhamnolipid fermentation by $P$. aeruginosa was generally carried out in weak alkaline conditions caused by the alkaline substances of microbial metabolism (Fig. S1), based on the foaming properties of rhamnolipid in 3.4 .2 and 3.4.3, which were conducive to enhance the foaming ability of rhamnolipid during fermentation. However, aqueous solution of rhamnolipid was weak acid (the 
value of $\mathrm{pH}$ was about 4.5 in our study) due to the existence of the carboxylic acid moiety [11, 46], which made rhamnolipid molecules low foaming. Therefore, it was advised that the solution of rhamnolipid used in foaming agent, emulsifier, oil recovery and other fields should be adjusted to neutral or alkaline.

\section{Conclusions}

The foaming behavior of fermentation broth of rhamnolipid produced by $P$. aeruginosa SW1 was confirmed to be typical $\mathrm{pH}$ dependency and the low-foaming fermentation of rhamnolipid could be realized at pH5.5. Effective low-foaming fermentation of rhamnolipid was realized by UV and EMS composite mutagenesis at $\mathrm{pH} 5.5$ and the mechanisms of low-foaming fermentation of rhamnolipid caused by weak acid $\mathrm{pH}$ were also systematically characterized. The work provided a guidance for further strain improvement of $P$. aeruginosa and developing a more effective $\mathrm{pH}$-associated control strategies for large-scale low-foaming production of rhamnolipid under weak-acid conditions.

\section{Abbreviations}

UV, ultraviolet

EMS, ethyl methanesulfonate

FA, Foaming ability

TEM, transmission electron microscopy

BC, Blue circle diameters/Colony diameters

CTAB, cetyltrimethylammonium bromide

\section{Declarations}

\section{Ethics approval and consent to participate}

Not applicable.

\section{Consent for publication}

Not applicable.

\section{Availability of data and materials}

Not applicable.

\section{Competing interests}

The authors declare that they have no competing interests. 


\section{Funding}

This research was supported by grant from Natural Science Foundation of Shandong Province (grant number ZR2019PB015).

\section{Authors' contributions}

ZG, CC, JL, MS and QH performed the experiments. GY supervised the project. ZG and QH drafted the manuscript. All authors read and approved the final manuscript.

\section{Acknowledgements}

This work was supported by Natural Science Foundation of Shandong Province (ZR2019PB015). We also would like to thank professor Qinhong Wang, Tianjin Institute of Industrial Biotechnology, Chinese Academy of Sciences, for providing guidance and experimental materials.

\section{References}

1. Varjani SJ, Upasani VN. Critical review on biosurfactant analysis, purification and characterization using rhamnolipid as a model biosurfactant. Bioresour Technol. 2017; 232:389-397.

2. Zhu L, Yang X, Xue C, Chen Y, Qu L, Lu W. Enhanced rhamnolipids production by Pseudomonas aeruginosa based on a pH stage-controlled fed-batch fermentation process. Bioresour Technol. 2012; 117:208-213.

3. Tan YN, Li Q. Microbial production of rhamnolipids using sugars as carbon sources. Microb Cell Fact. 2018; 17:1-13.

4. Zhao F, Zhang J, Shi R, Han S, Ma F, Zhang Y. Production of biosurfactant by a Pseudomonas aeruginosa isolate and its applicability to in situ microbial enhanced oil recovery under anoxic conditions. RSC Adv. 2015; 5:36044-36050.

5. Zhao F, Zhou J, Han S, Ma F, Zhang Y, Zhang J. Medium factors on anaerobic production of rhamnolipids by Pseudomonas aeruginosa SG and a simplifying medium for in situ microbial enhanced oil recovery applications. World J Microbiol Biotechnol. 2016; 32:54-54.

6. Sun S, Wang Y, Zang T, Wei J, Wu H, Wei C, Qiu G, Li F. A biosurfactant-producing Pseudomonas aeruginosa 5 isolated from coking wastewater and its application for bioremediation of polycyclic aromatic hydrocarbons. Bioresour Technol. 2019; 281:421-428.

7. Nitschke M, Costa SGVAO. Biosurfactants in food industry. Trends Food Sci Tech. 2007; 18:252-259.

8. Kiran GS, Priyadharsini S, Sajayan A, Priyadharsini GB, Poulose N, Selvin J. Production of lipopeptide biosurfactant by a marine nesterenkonia sp. and its application in food industry. Fact Microbiol. 2017; 8:1138-1138.

9. Yi G, Son J, Yoo J, Park C, Koo H. Rhamnolipid nanoparticles for in vivo drug delivery and photodynamic therapy. Nanomed Nanotechnol Biol Med. 2019; 19:12-21. 
10. Chen J, Wu Q, Hua Y, Chen J, Zhang H, Wang H. Potential applications of biosurfactant rhamnolipids in agriculture and biomedicine. Appl Microbiol Biotechnol. 2017; 101:8309-8319.

11. Sodagari M, Ju LK. Cells Were a More Important Foaming Factor than Free Rhamnolipids in fermentation of Pseudomonas aeruginosa E03-40 for high rhamnolipid production. J Surfactants Deterg. 2014; 17:573-582.

12. Gong Z, Peng Y, Wang Q. Rhamnolipid production, characterization and fermentation scale-up by Pseudomonas aeruginosa with plant oils. Biotechnol Lett. 2015; 37:2033-2038.

13. Long $X$, Sha R, Meng Q, Zhang G. Mechanism study on the severe foaming of rhamnolipid in fermentation. J Surfactants Deterg. 2016; 19:833-840.

14. Gong Z, He Q, Che C, Liu J, Yang G. Optimization and scale-up of the production of rhamnolipid by Pseudomonas aeruginosa in solid-state fermentation using high-density polyurethane foam as an inert support. Bioproc Biosyst Eng. 2020; 43:385-392.

15. Zhao F, Shi R, Zhao J, Li G, Bai X, Han S, Zhang Y. Heterologous production of Pseudomonas aeruginosa rhamnolipid under anaerobic conditions for microbial enhanced oil recovery. J Appl Microbiol. 2015; 118:379-389.

16. Pinzon NM, Cook AG, Ju L. Continuous rhamnolipid production using denitrifying Pseudomonas aeruginosa cells in hollow-fiber bioreactor. Biotechnol Prog. 2013; 29:352-358.

17. Camiliosneto D, Bugay C, Santanafilho AP, Joslin T, De Souza LM, Sassaki GL, Mitchell DA, Krieger N. Production of rhamnolipids in solid-state cultivation using a mixture of sugarcane bagasse and corn bran supplemented with glycerol and soybean oil. Appl Microbiol Biotechnol. 2011; 89:1395-1403.

18. Neto DC, Meira JA, De Araujo JM, Mitchell DA, Krieger N. Optimization of the production of rhamnolipids by Pseudomonas aeruginosa UFPEDA 614 in solid-state culture. Appl Microbiol Biotechnol. 2008; 81:441-448.

19. Long X, Shen C, He N, Zhang G, Meng Q. Enhanced rhamnolipids production via efficient foamcontrol using stop valve as a foam breaker. Bioresour Technol. 2017; 224:536-543.

20. Heyd M, Franzreb M, Berensmeier S. Continuous rhamnolipid production with integrated product removal by foam fractionation and magnetic separation of immobilized Pseudomonas aeruginosa. Biotechnol Prog. 2011; 27:706-716.

21. Willenbacher J, Zwick M, Mohr T, Schmid F, Syldatk C, Hausmann R. Evaluation of different Bacillus strains in respect of their ability to produce Surfactin in a model fermentation process with integrated foam fractionation. Appl Microbiol Biotechnol. 2014; 98:9623-9632.

22. Anic I, Apolonia I, Franco P, Wichmann R. Production of rhamnolipids by integrated foam adsorption in a bioreactor system. AMB Express. 2018; 8:122.

23. Anic I, Nath A, Franco P, Wichmann R. Foam adsorption as an ex situ capture step for surfactants produced by fermentation. J Biotechnol. 2017; 258:181-189.

24. Sodagari M, Invally K, Ju L. Maximize rhamnolipid production with low foaming and high yield. Enzyme Microb Technol. 2018; 110:79-86. 
25. Wu J, Ju L. Extracellular particles of polymeric material formed in $\mathrm{n}$-hexadecane fermentation by Pseudomonas aeruginosa. J Biotechnol. 1998; 59:193-202.

26. Wang Q, Fang X, Bai B, Liang X, Shuler PJ, Goddard III WA, Tang Y. Engineering bacteria for production of rhamnolipid as an agent for enhanced oil recovery. Biotechnol Bioeng. 2007; 98:842853.

27. Wang Q, Fang X, Bai B, Liang X, Shuler PJ, Goddard WA, 3rd, Tang Y. Engineering bacteria for production of rhamnolipid as an agent for enhanced oil recovery. Biotechnol Bioeng. 2007; 98:842853.

28. Xiong T, Xiong W, Ge M, Xia J, Li B, Chen Y. Effect of high intensity ultrasound on structure and foaming properties of pea protein isolate. Food Res Int. 2018; 109:260-267.

29. Siegmund I, Wagner F. New method for detecting rhamnolipids excreted by Pseudomonas species during growth on mineral agar. Biotechnol Tech. 1991; 5:265-268.

30. O'Sullivan J, Arellano M, Pichot R, Norton I. The effect of ultrasound treatment on the structural, physical and emulsifying properties of dairy proteins. Food Hydrocolloid. 2014; 42:386-396.

31. Saint-Jalmes A, Langevin D. Time evolution of aqueous foams: drainage and coarsening. J PhysCondens Mat. 2002; 14:9397.

32. Guo F, Li Y, Xu H-X, Zhao G-Q, He X-J. Size-controllable synthesis of calcium carbonate nanoparticles using aqueous foam films as templates. Mat Lett. 2007; 61:4937-4939.

33. Chen S-Y, Wei Y-H, Chang J-S. Repeated $\mathrm{pH}$-stat fed-batch fermentation for rhamnolipid production with indigenous Pseudomonas aeruginosa S2. Appl Microbiol Biotechnol. 2007; 76:67-74.

34. Jiang J, Zu Y, Li X, Meng Q, Long X. Recent progress towards industrial rhamnolipids fermentation: Process optimization and foam control. Bioresour Technol. 2020; 298:122394.

35. Kanazir DT, Hartman PE, Savic DJ. Ultraviolet-induced reversions of Salmonella his frameshift mutations. J Bacteriol. 1970; 101:649-651.

36. Gao X, Jiang L, Zhu L, Xu Q, Xu X, Huang H. Tailoring of global transcription sigma D factor by random mutagenesis to improve Escherichia coli tolerance towards low-pHs. J Biotechnol. 2016; 224:55-63.

37. Noh MH, Lim HG, Woo SH, Song J, Jung GY. Production of itaconic acid from acetate by engineering acid-tolerant Escherichia coli W. Biotechnol Bioeng. 2018; 115:729-738.

38. Cai C, Liu H, Xi X, Jia M, Yin H. Bubble growth model in uniformly superheated binary liquid mixture. International Journal of Heat and Mass Transfer. 2018; 127:629-638.

39. Cicutti C, Valdez M, Perez T, Donayo R, Petroni J. Analysis of slag foaming during the operation of an industrial converter. Lat Am Appl Res. 2002; 32:237-240.

40. Yuan H, Liu Z, Ren J. Preparation, characterization, and foaming behavior of poly (lactic acid)/poly (butylene adipate-co-butylene terephthalate) blend. Polym Eng Sci. 2009; 49:1004-1012.

41. Helvacı Ş, Peker S, Özdemir G. Effect of electrolytes on the surface behavior of rhamnolipids R1 and R2. Colloids Surf B Biointerfaces. 2004; 35:225-233. 
42. Raza ZA, Khalid ZM, Khan MS, Banat IM, Rehman A, Naeem A, Saddique MT. Surface properties and sub-surface aggregate assimilation of rhamnolipid surfactants in different aqueous systems. Biotechnol Lett. 2010; 32:811-816.

43. Lebrón-Paler A, Pemberton JE, Becker BA, Otto WH, Larive CK, Maier RM. Determination of the acid dissociation constant of the biosurfactant monorhamnolipid in aqueous solution by potentiometric and spectroscopic methods. Anal chem. 2006; 78:7649-7658.

44. Farahat M, Hirajima T, Sasaki K, Doi K. Adhesion of Escherichia coli onto quartz, hematite and corundum: Extended DLVO theory and flotation behavior. Colloid Surf B. 2009; 74:140-149.

45. Lebronpaler A, Pemberton JE, Becker BA, Otto WH, Larive CK, Maier RM. Determination of the acid dissociation constant of the biosurfactant monorhamnolipid in aqueous solution by potentiometric and spectroscopic Methods. Anal Chem. 2006; 78:7649-7658.

46. Ishigami Y, Gama Y, Nagahora H, Yamaguchi M, Nakahara H, Kamata T. The pH-Sensitive conversion of molecular aggregates of rhamnolipid biosurfactant. Chem Lett. 1987; 16:763-766.

47. Urum K, Pekdemir T, Ross D, Grigson S. Crude oil contaminated soil washing in air sparging assisted stirred tank reactor using biosurfactants. Chemosphere. 2005; 60:334-343.

48. Urum K, Pekdemir T. Evaluation of biosurfactants for crude oil contaminated soil washing. Chemosphere. 2004; 57:1139-1150.

\section{Figures}



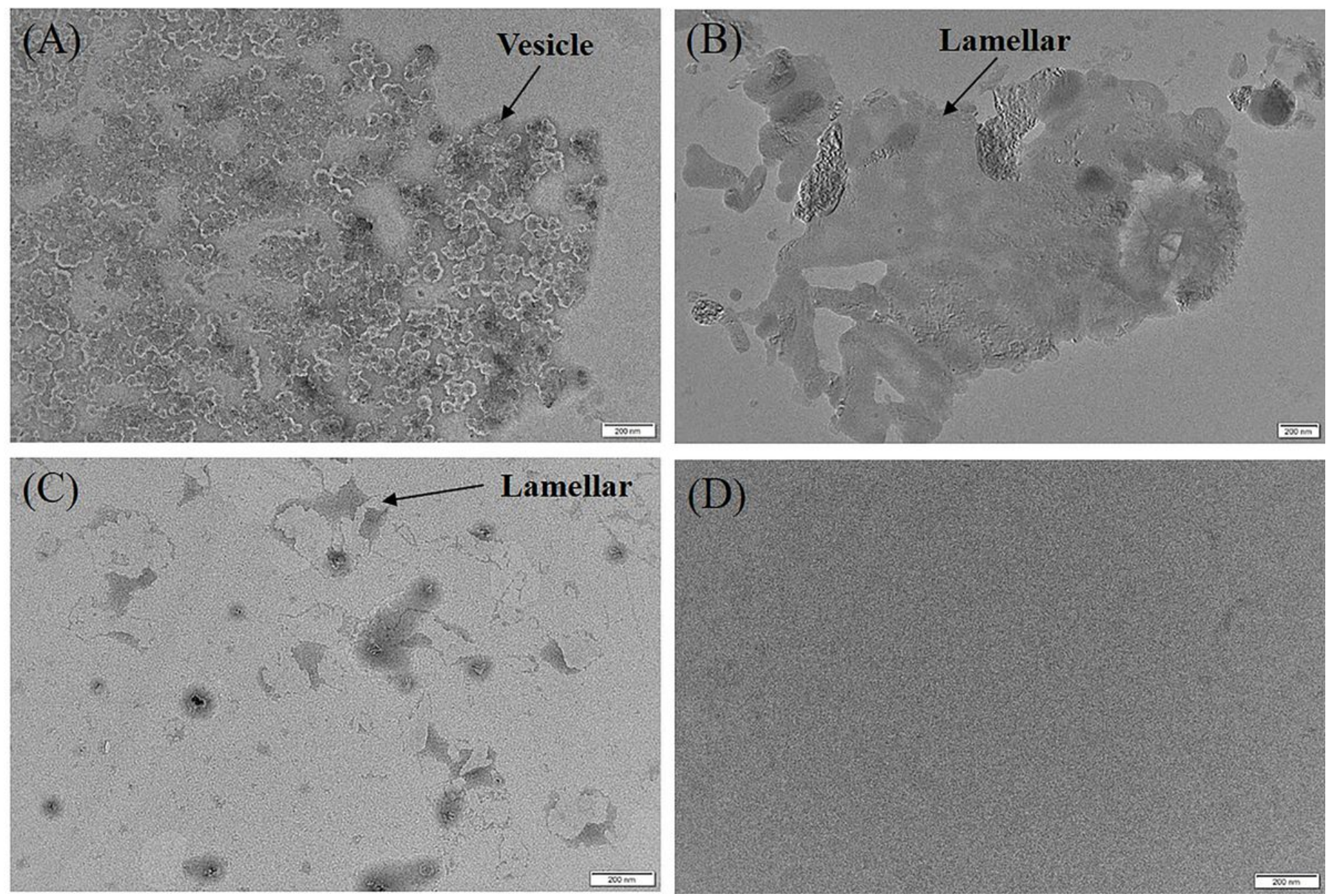

Figure 1 
(A)
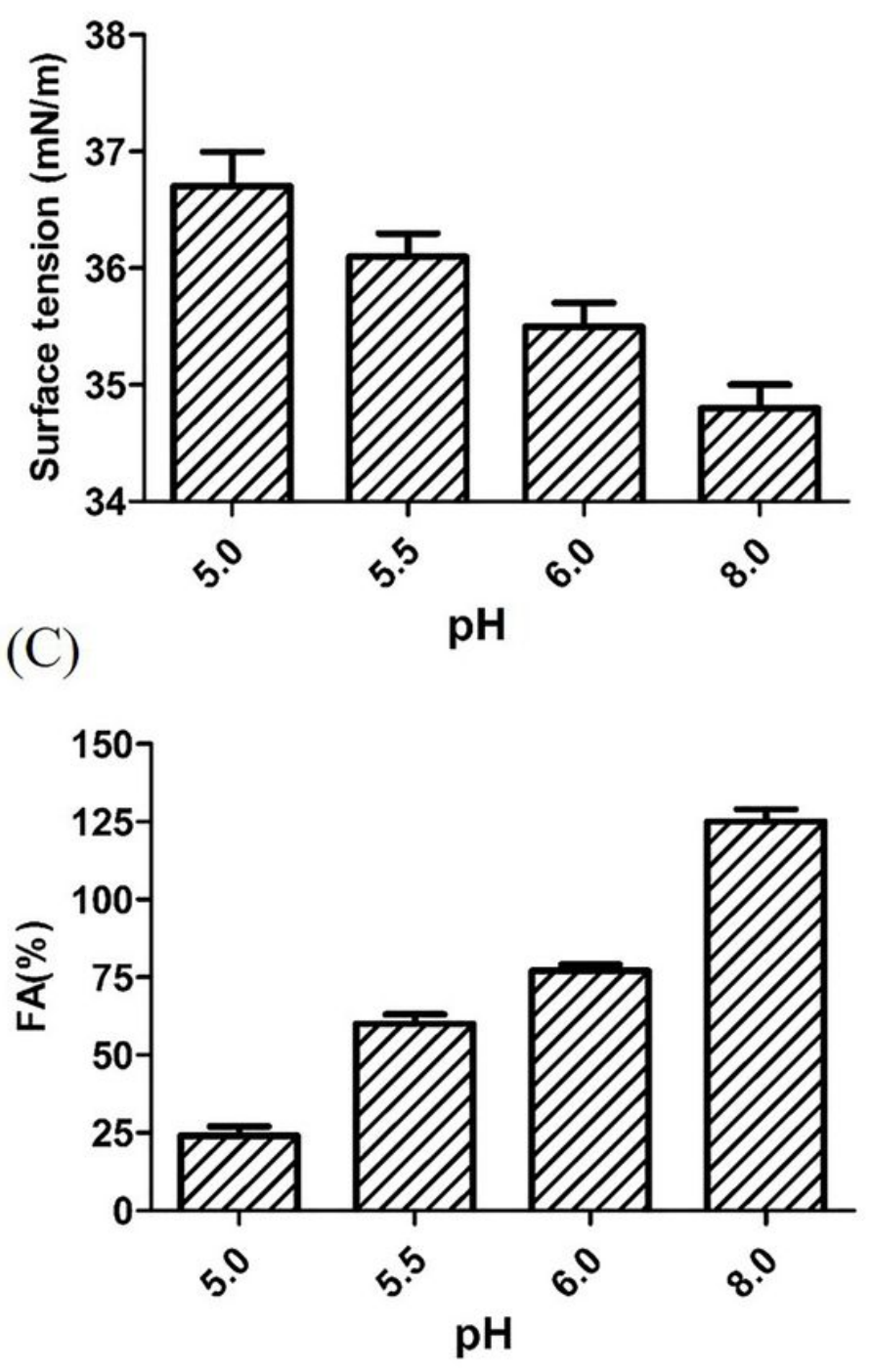

(B)
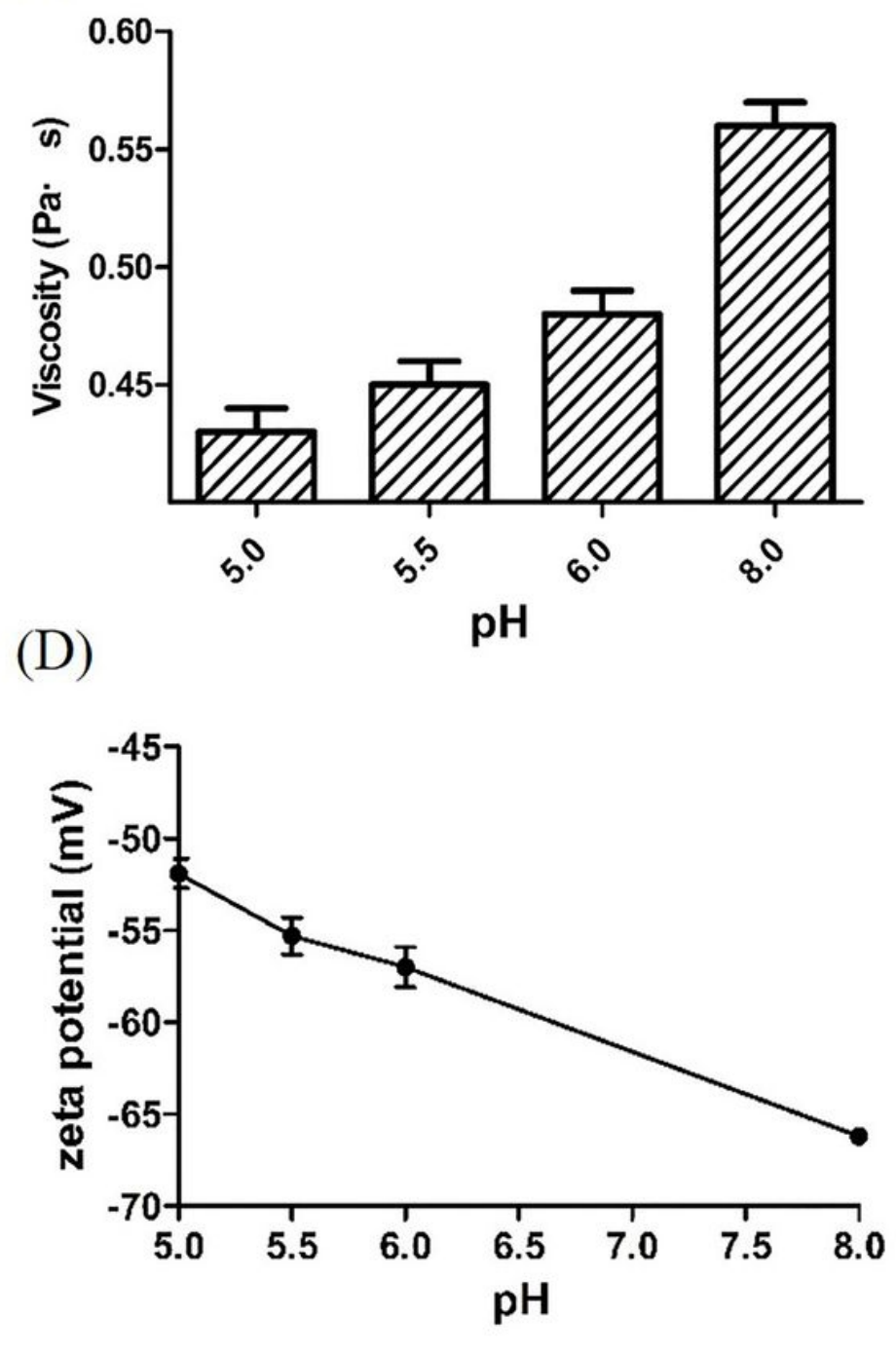

Figure 2 
(A)

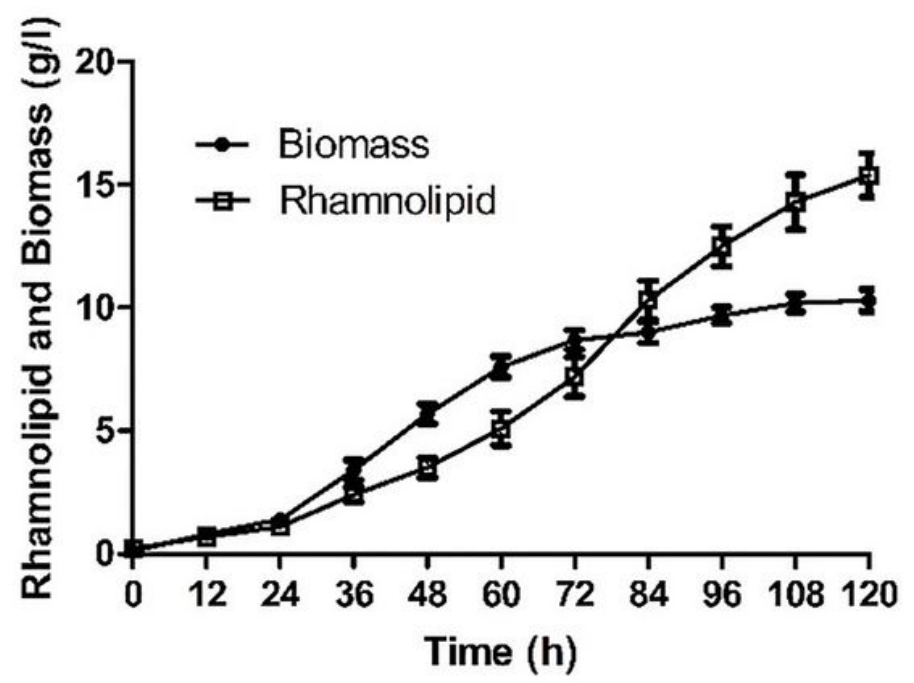

(B)

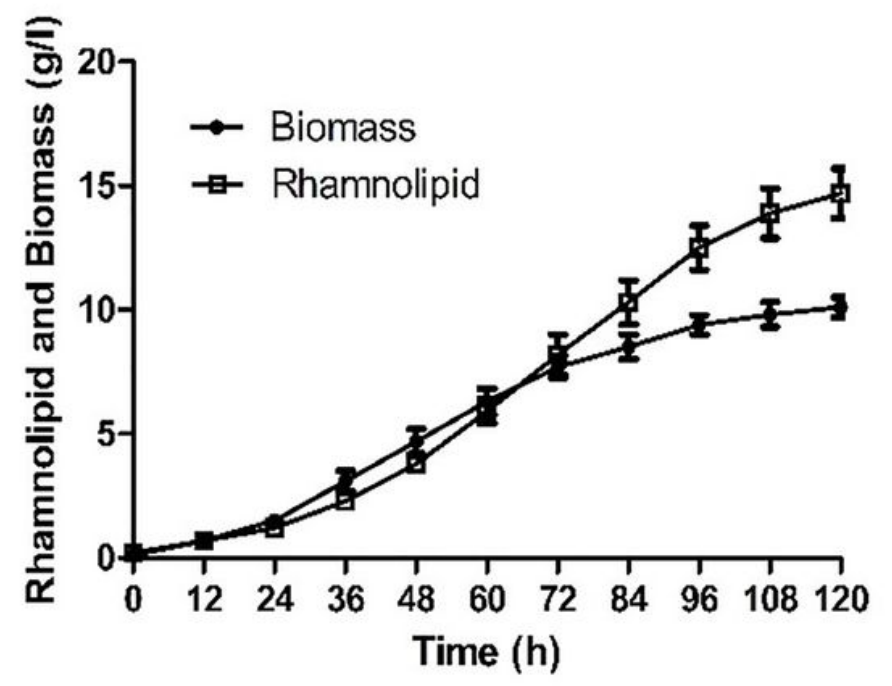

Figure 3 
(A)
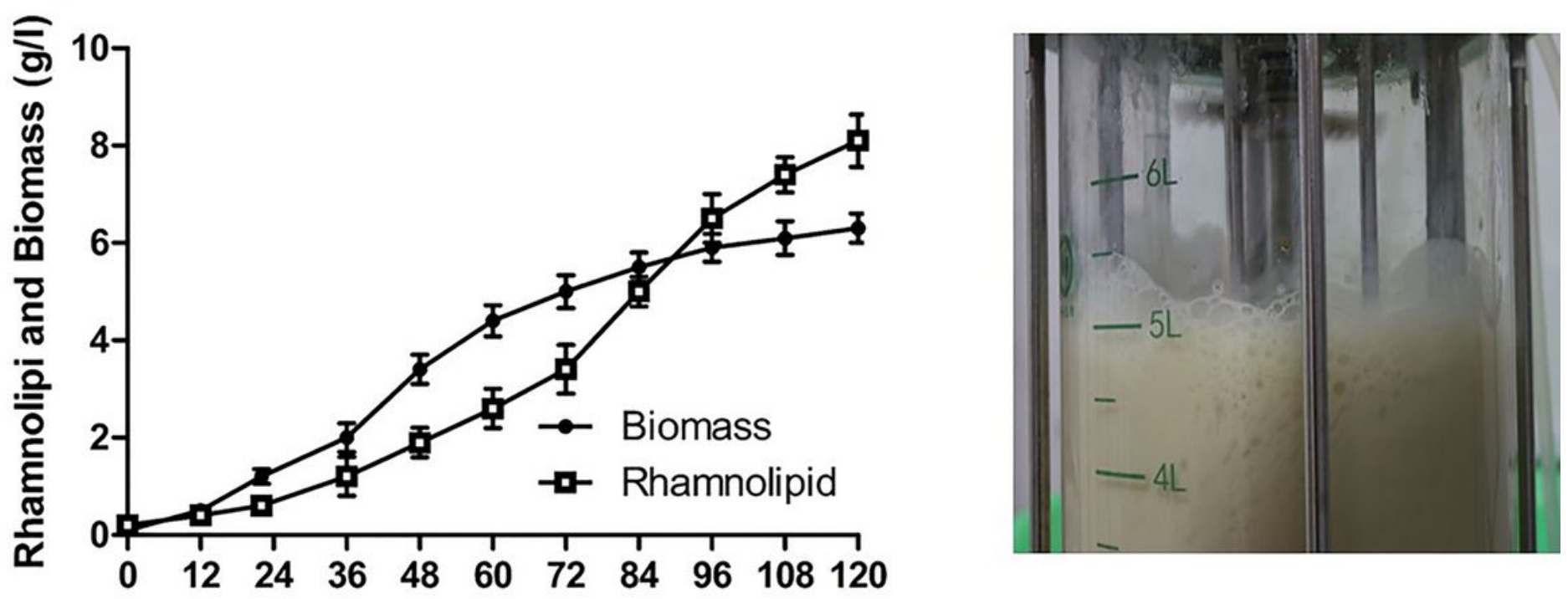

Time (h)

(B)
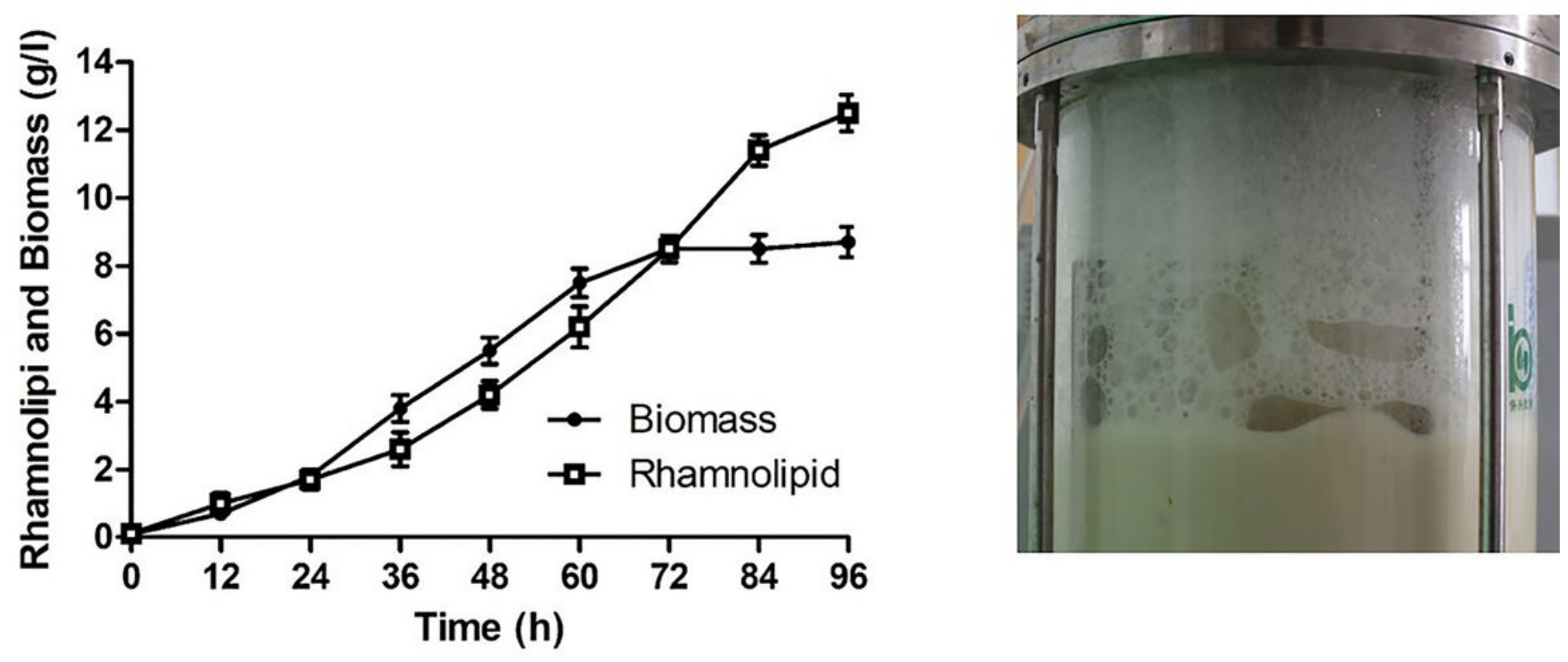

Figure 4 
$1 \mathrm{~min}$
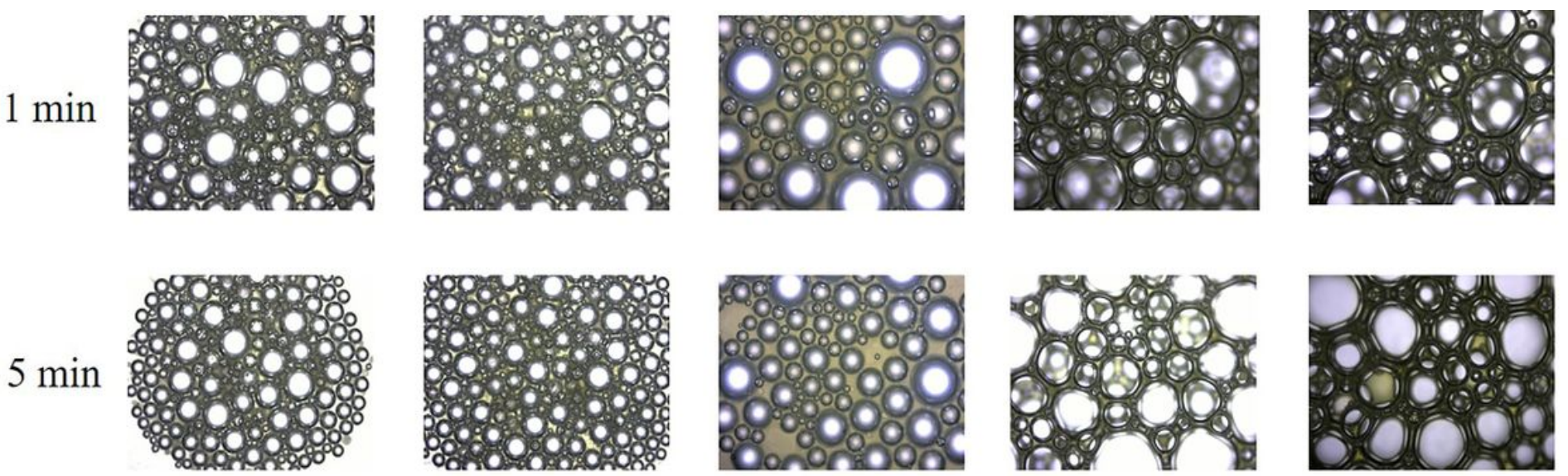

$\mathrm{pH} 4$

pH5

(C)

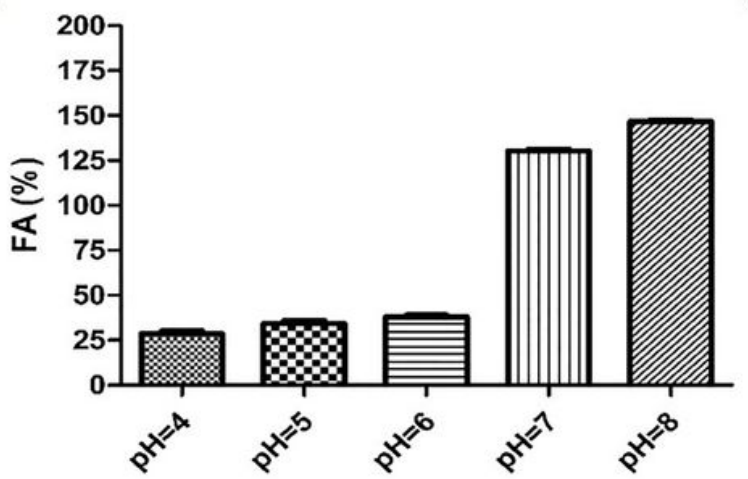

(B)

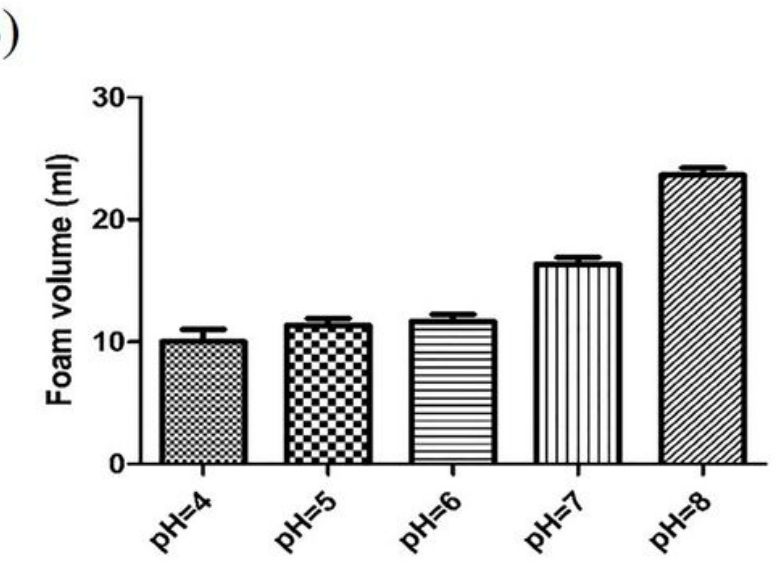

(A)
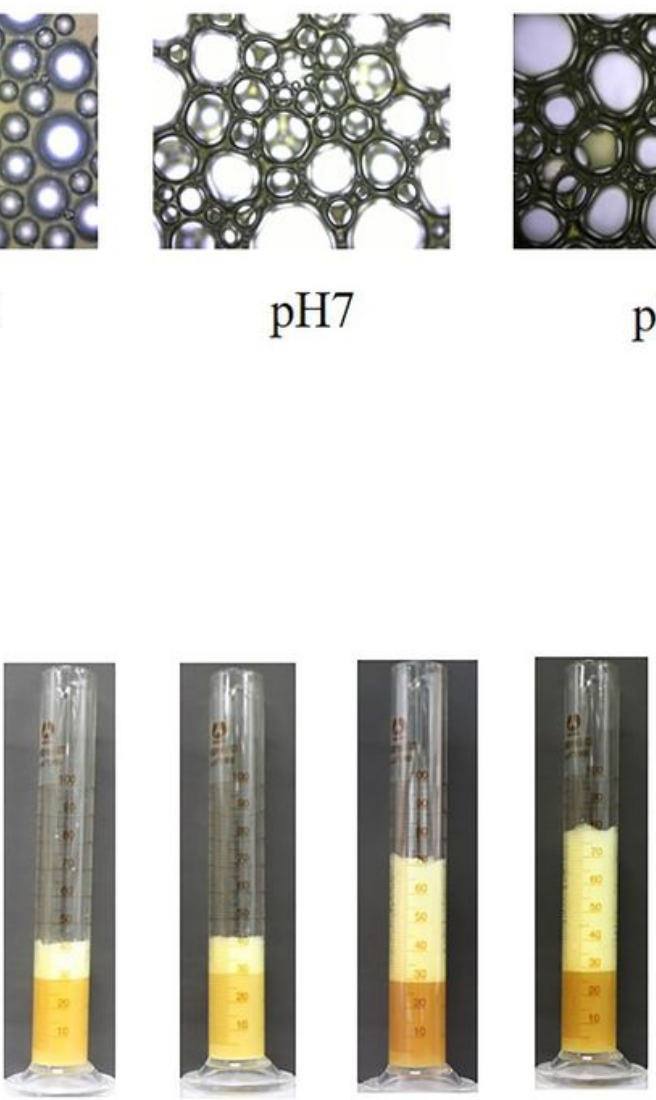

$1 \mathrm{~min}$

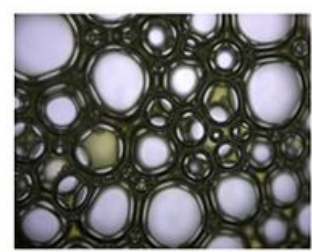

$\mathrm{pH} 8$

Figure 5
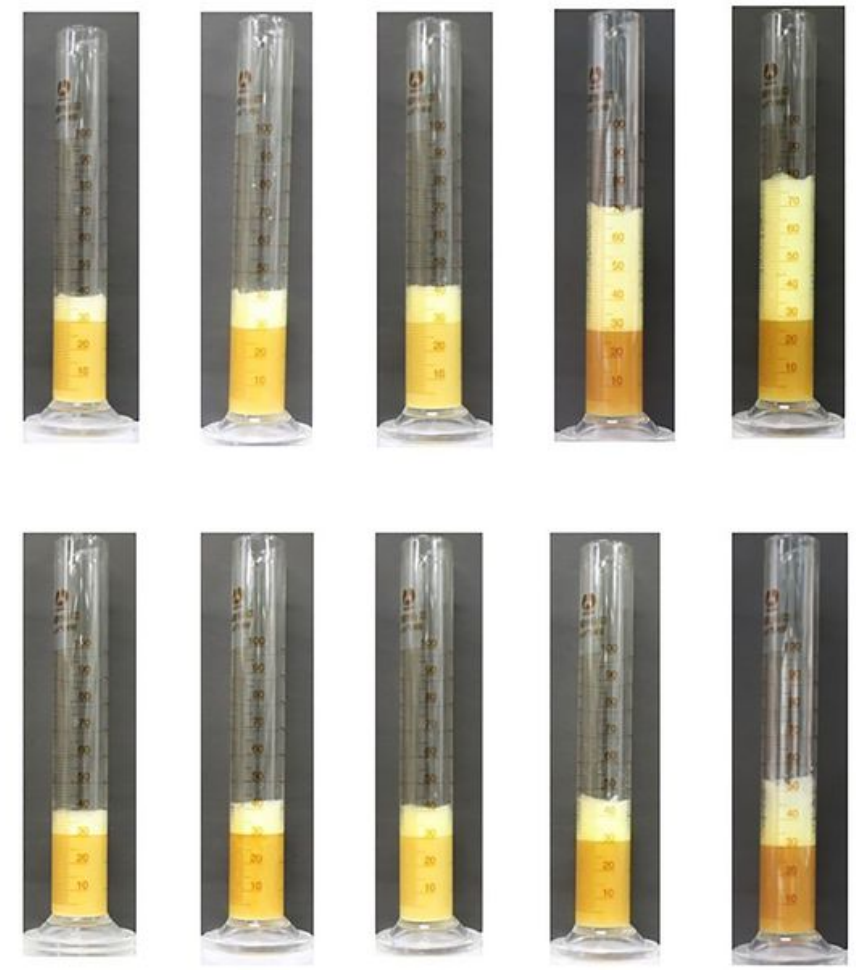

$5 \mathrm{~min}$

Figure 6 
(A)

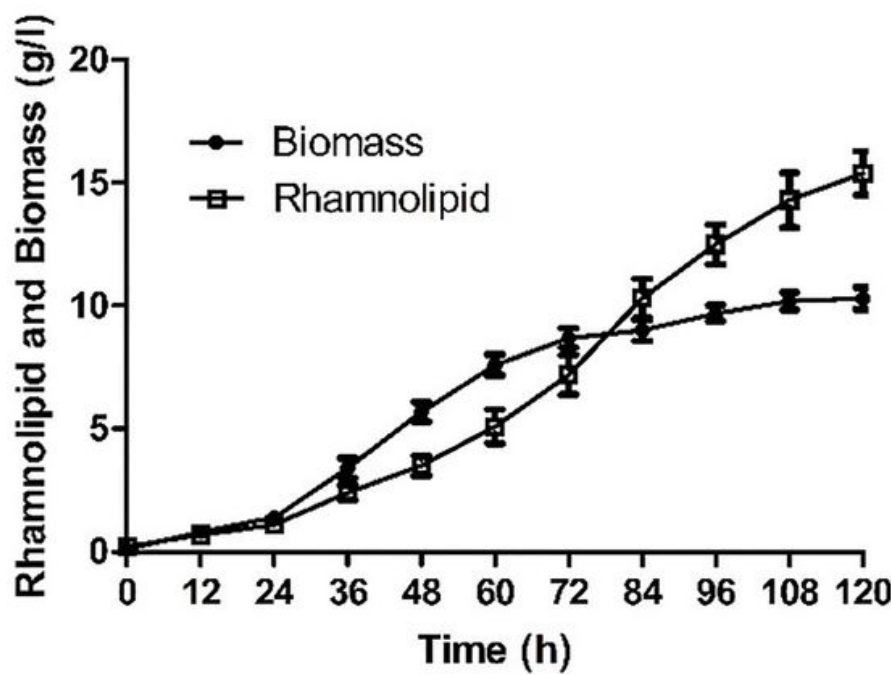

Figure 7

(A)

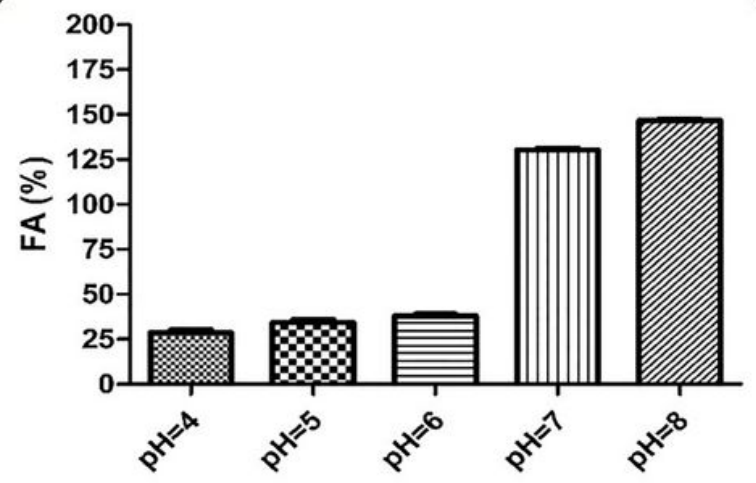

(B)

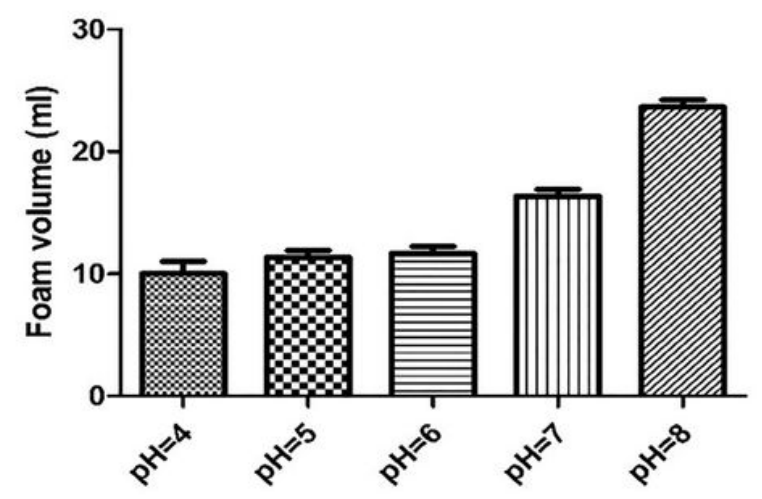

(B)

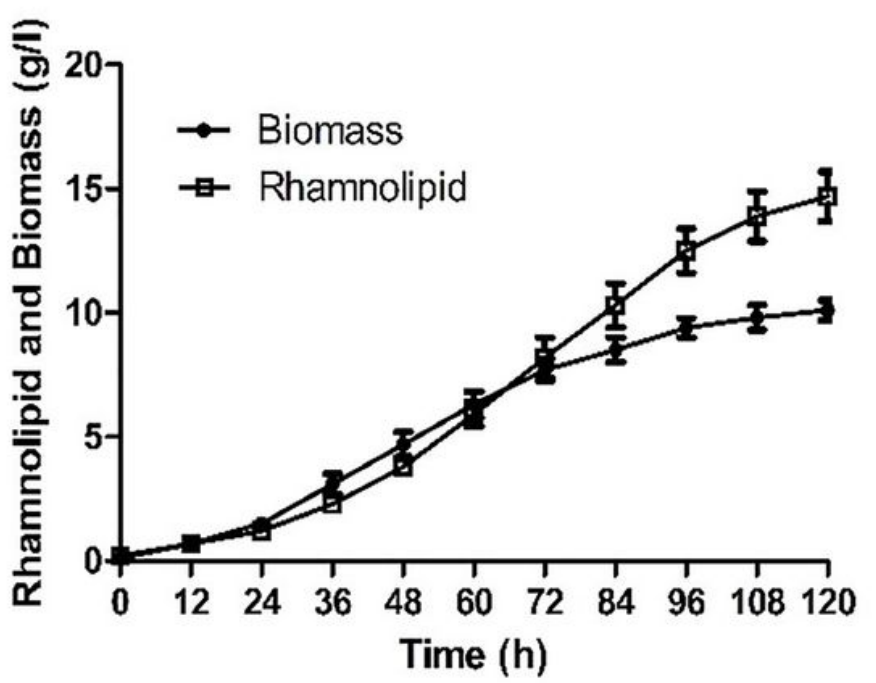

(C)
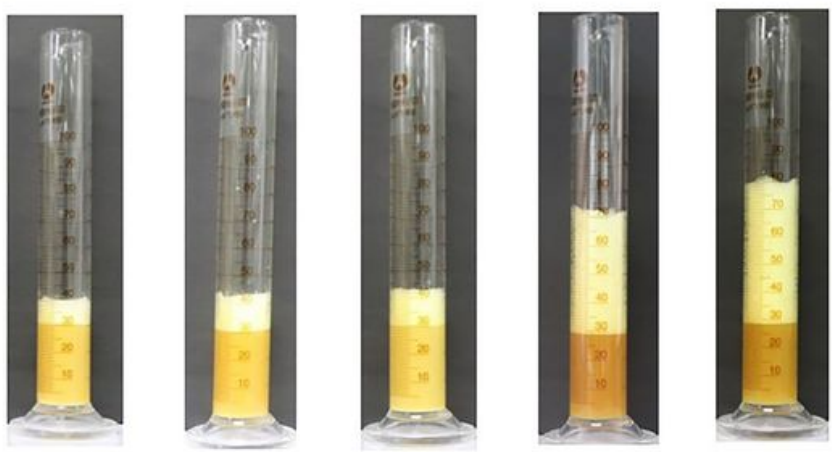

$1 \mathrm{~min}$
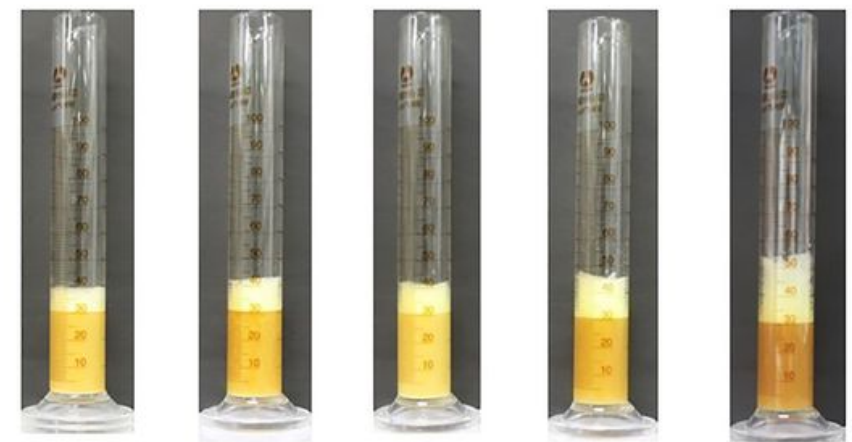

$\mathrm{pH}=4$

$\mathrm{pH}=5$

$\mathrm{pH}=6$

$5 \mathrm{~min}$

Figure 8 

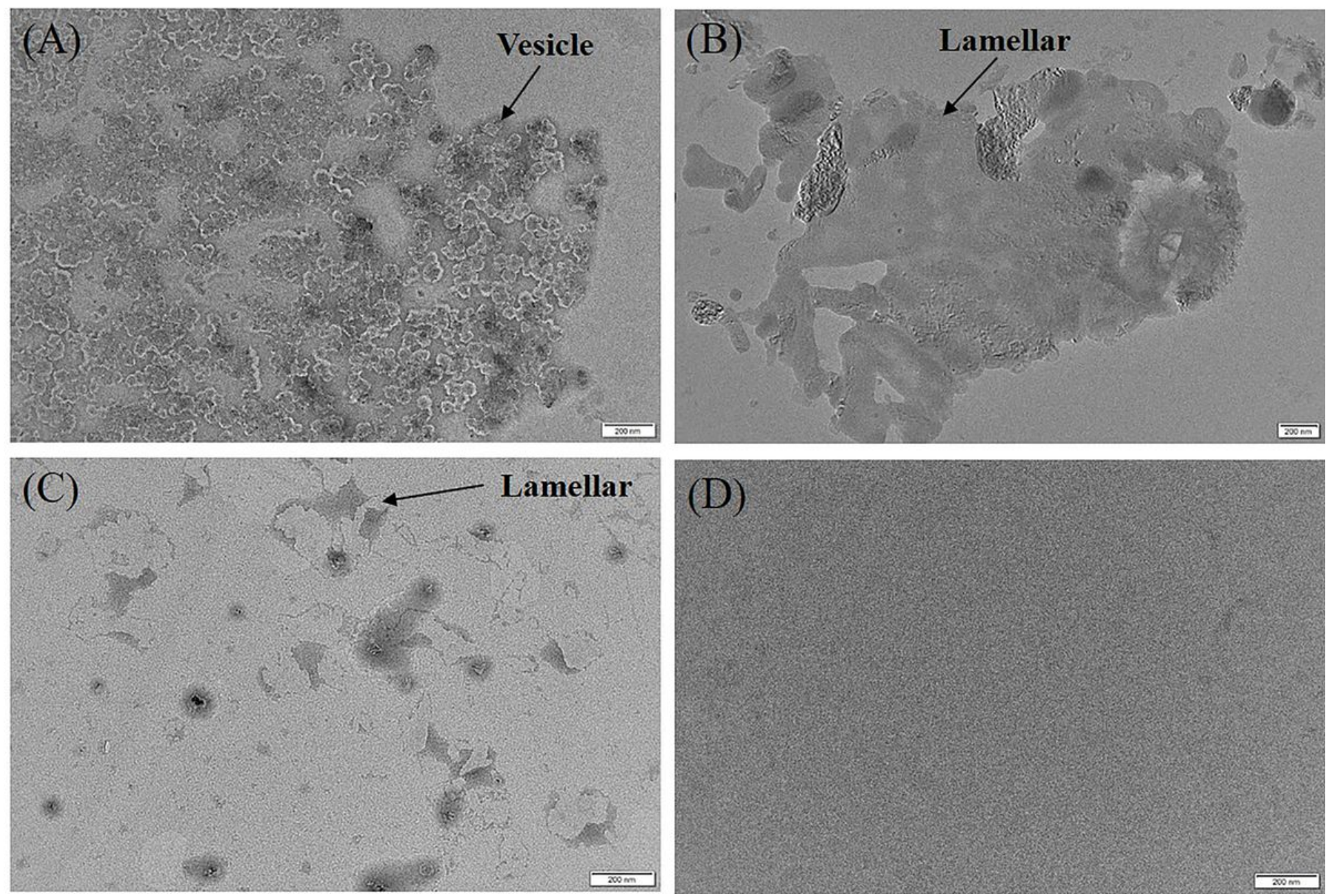

Figure 9 
(A)

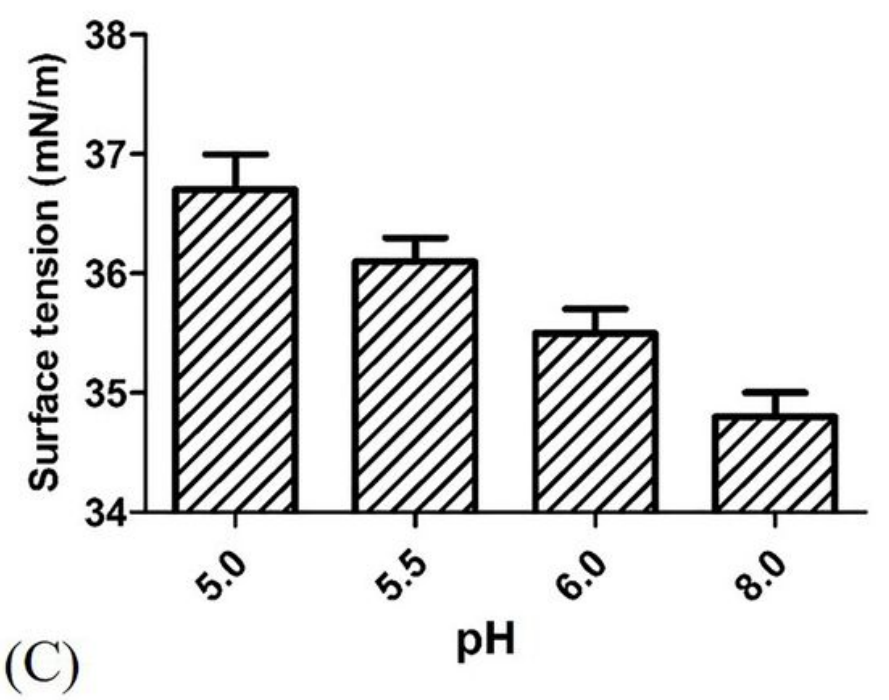

(C)

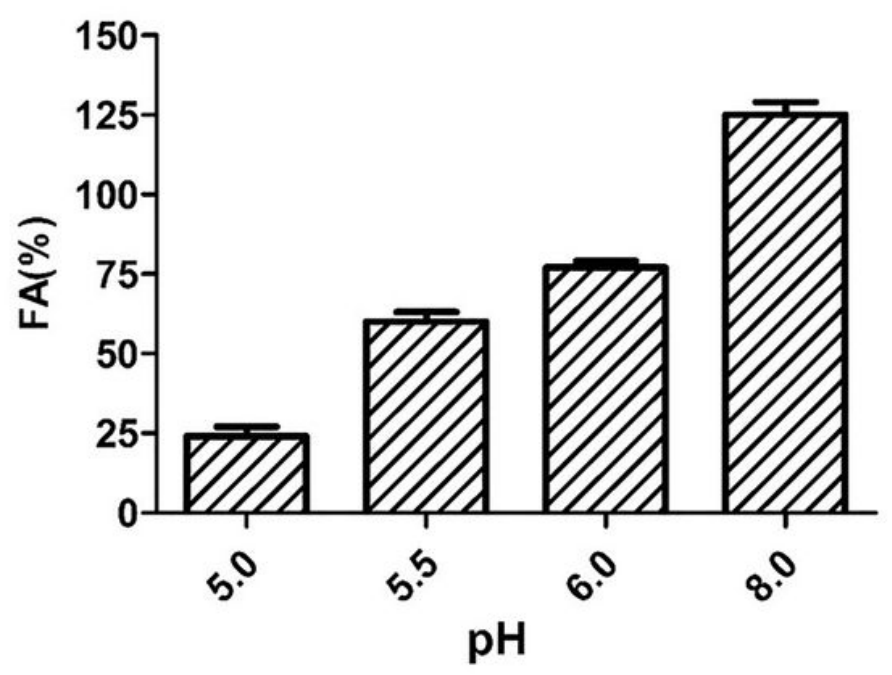

(B)
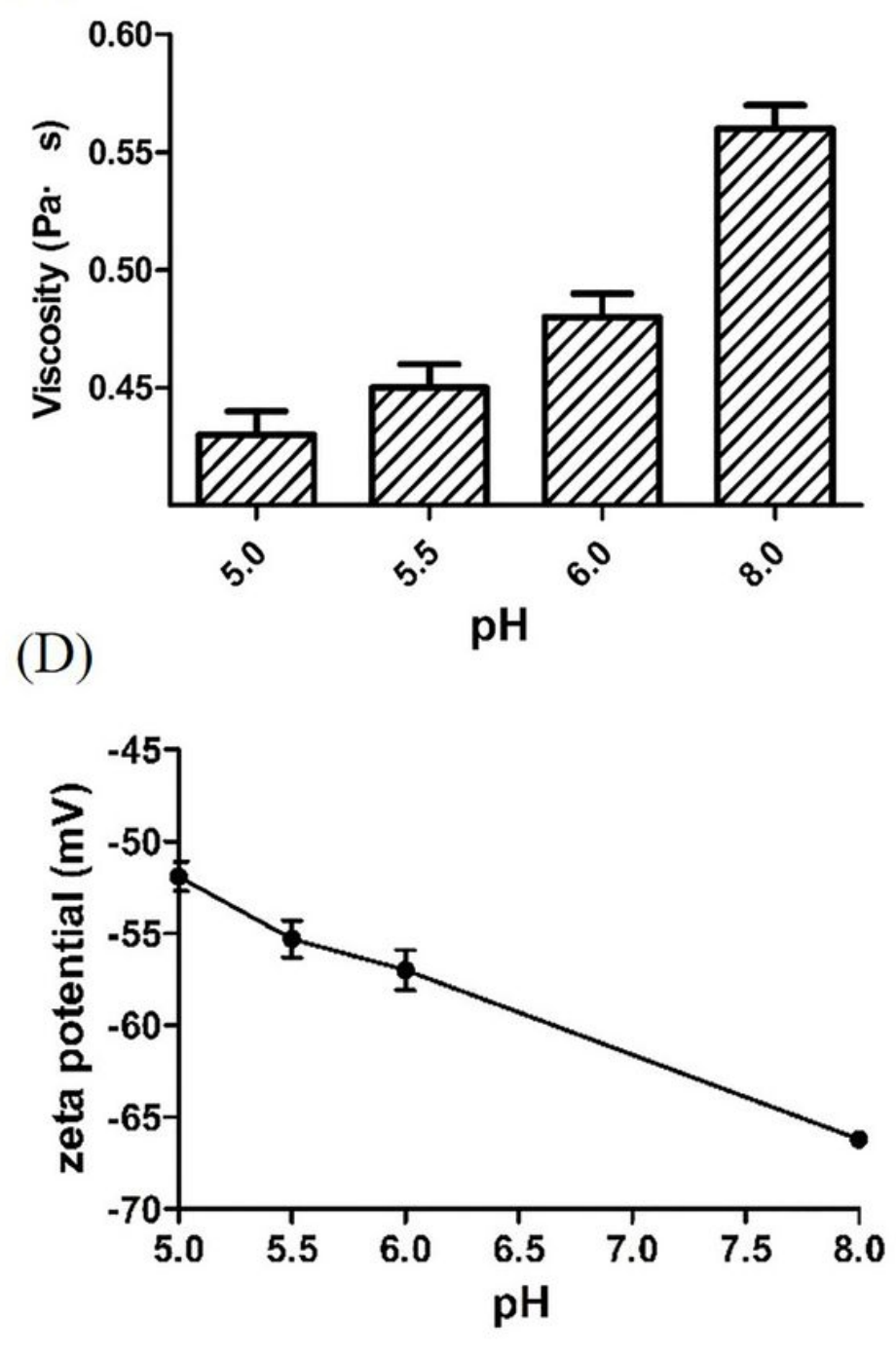

Figure 10 
(A)
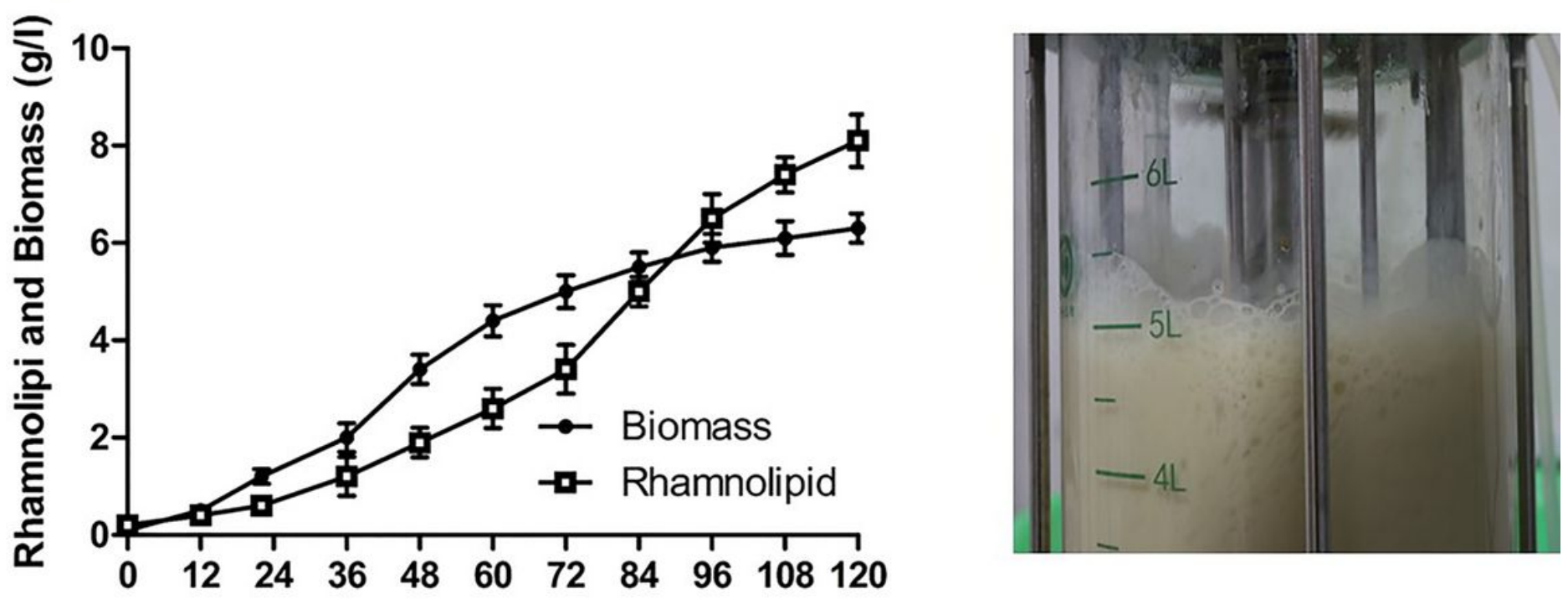

Time (h)

(B)
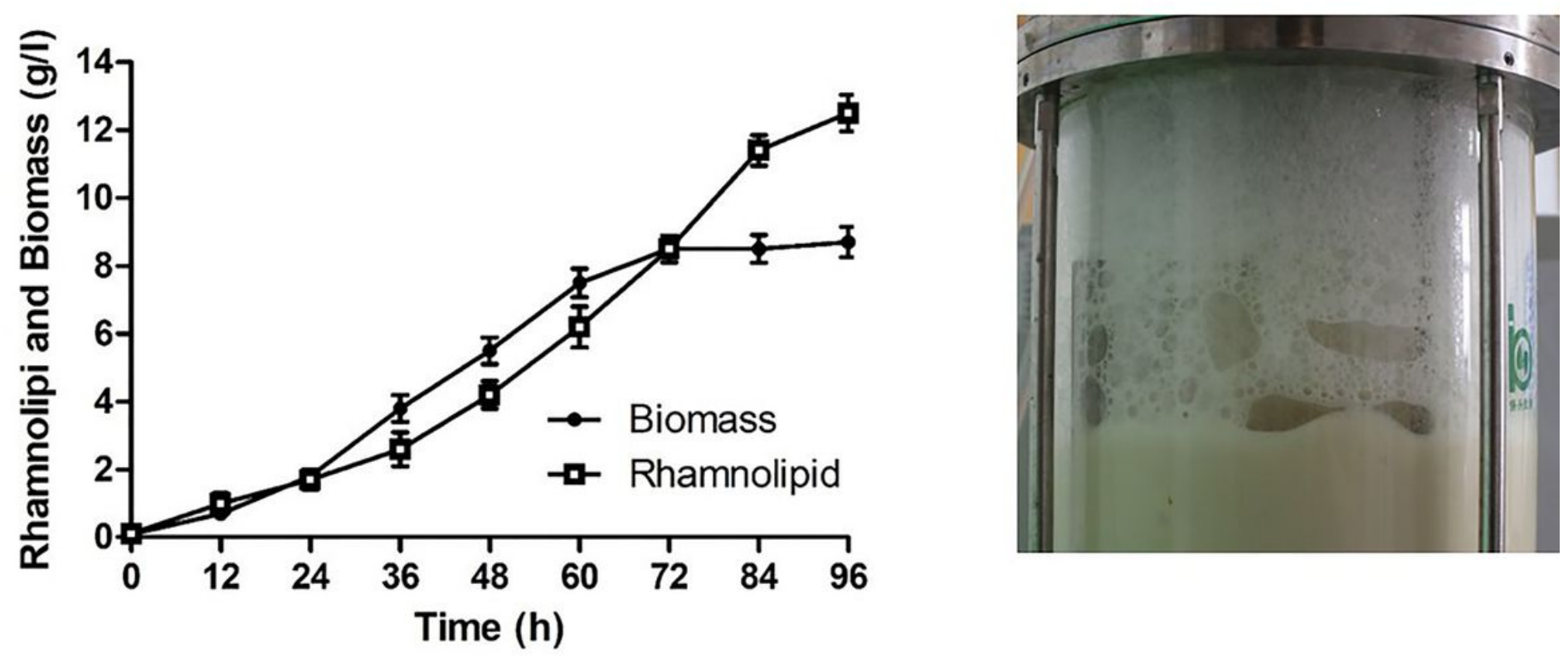

Figure 11 
$1 \mathrm{~min}$

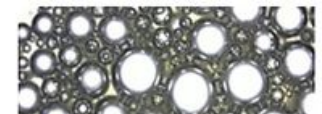

.... 8.

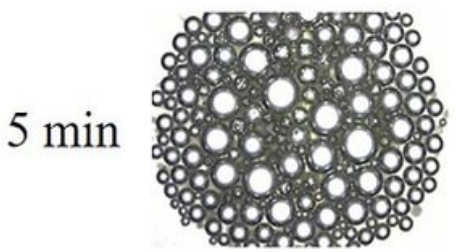

pH4
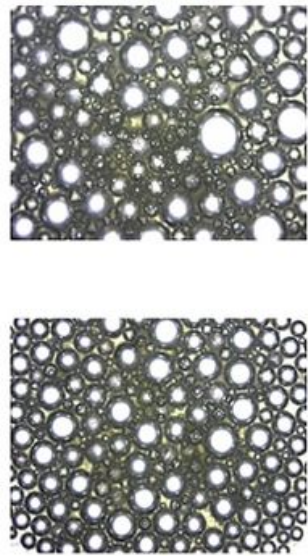

pH5
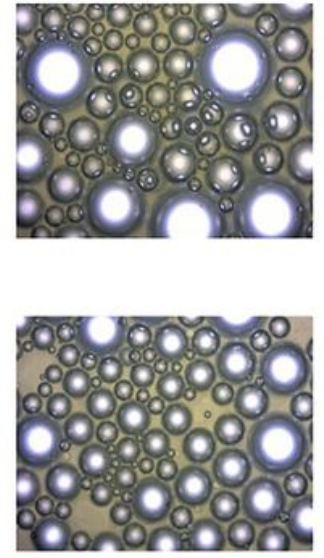

pH6
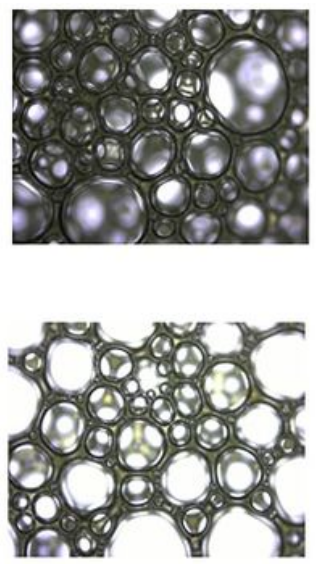

$\mathrm{pH} 7$
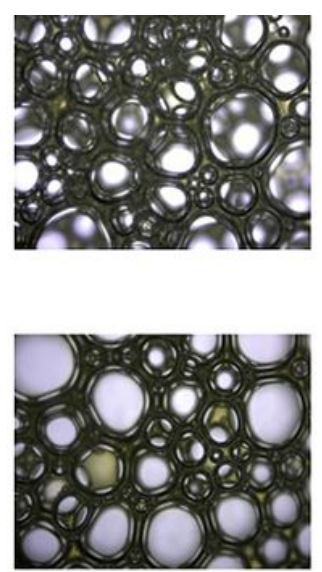

pH8

Figure 12

(A)

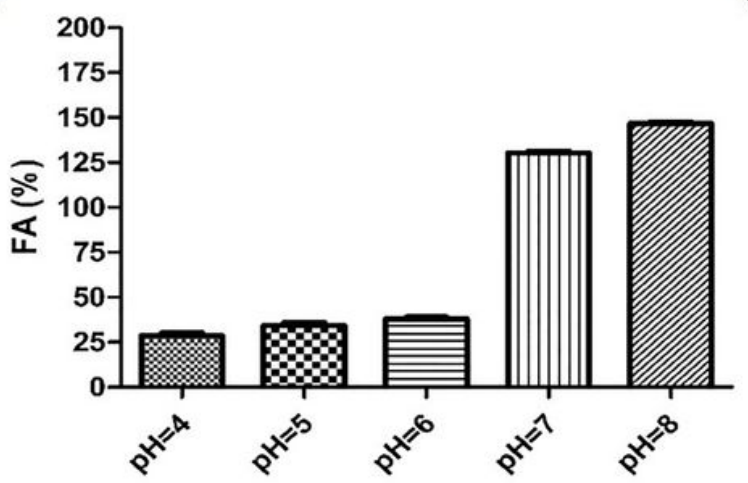

(B)

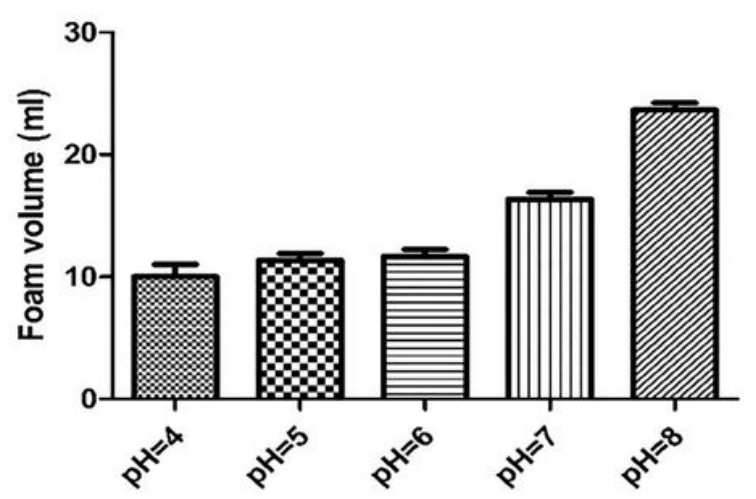

(C)
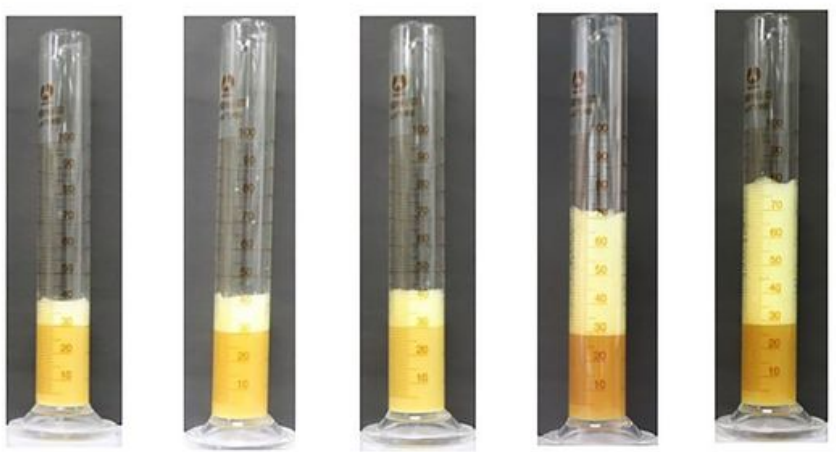

$1 \mathrm{~min}$
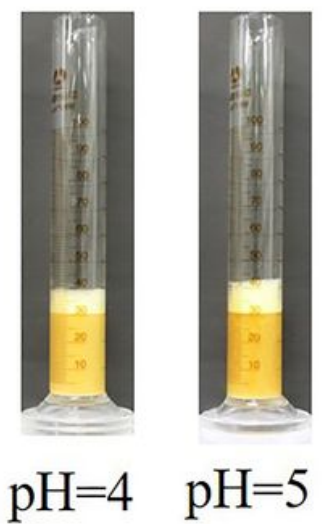
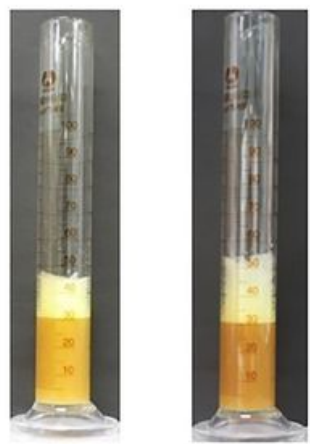

$5 \min$

Figure 13

FA of fermentation broth of rhamnolipid (A), foam volume at $5 \mathrm{~min}(\mathrm{~B})$ and visual foam volume image after being stored at 1 and 5 min (C). 
$1 \mathrm{~min}$
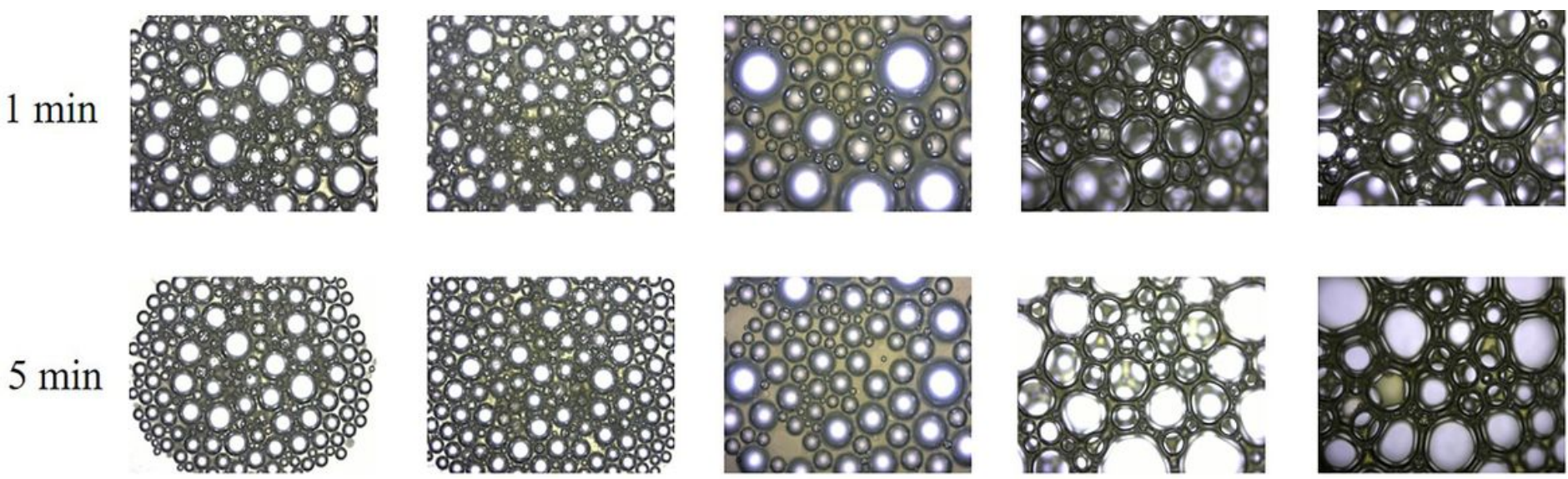

$\mathrm{pH} 4$

$\mathrm{pH} 5$

pH6

$\mathrm{pH} 7$

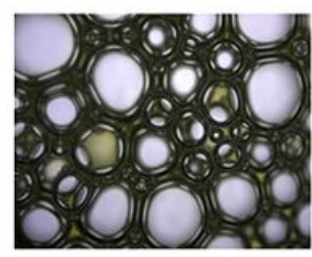

$\mathrm{pH} 8$

\section{Figure 14}

Time evolution of air bubbles within foams formed by fermentation broth of rhamnolipid from $\mathrm{pH} 4$ to pH8. All images were obtained at the same magnification. 
(A)
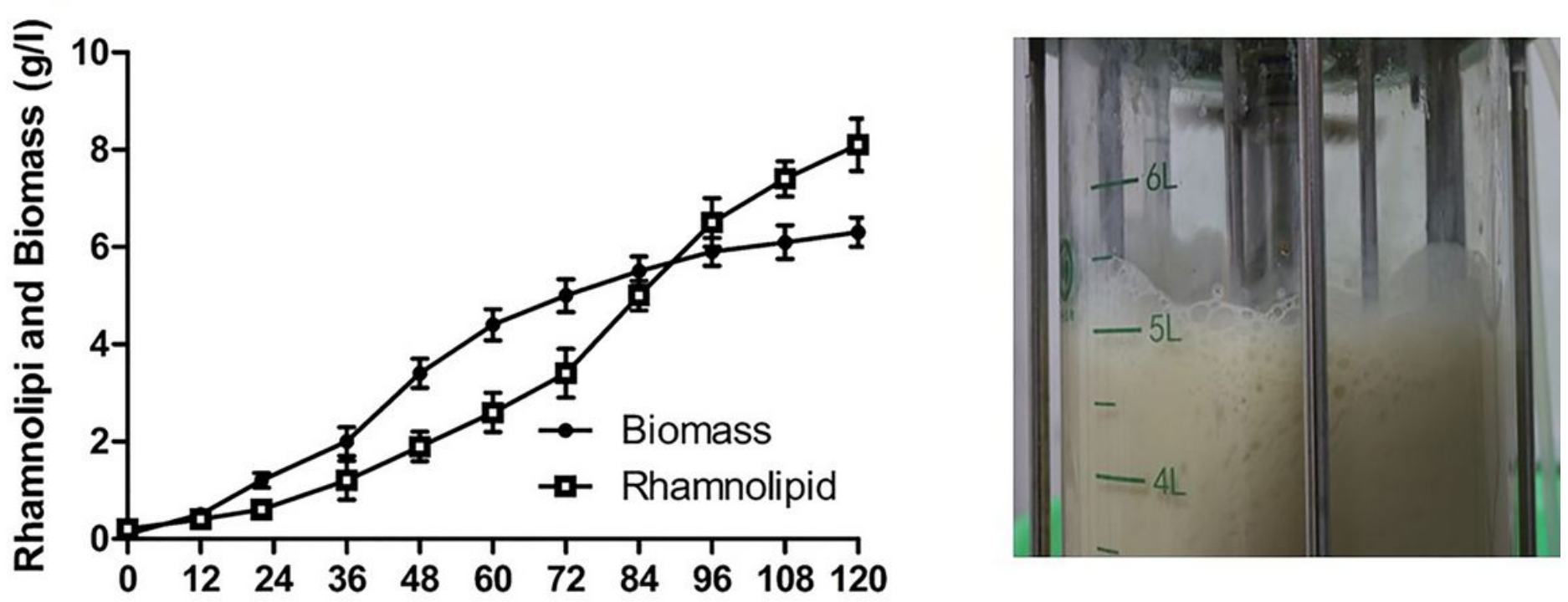

Time (h)

(B)
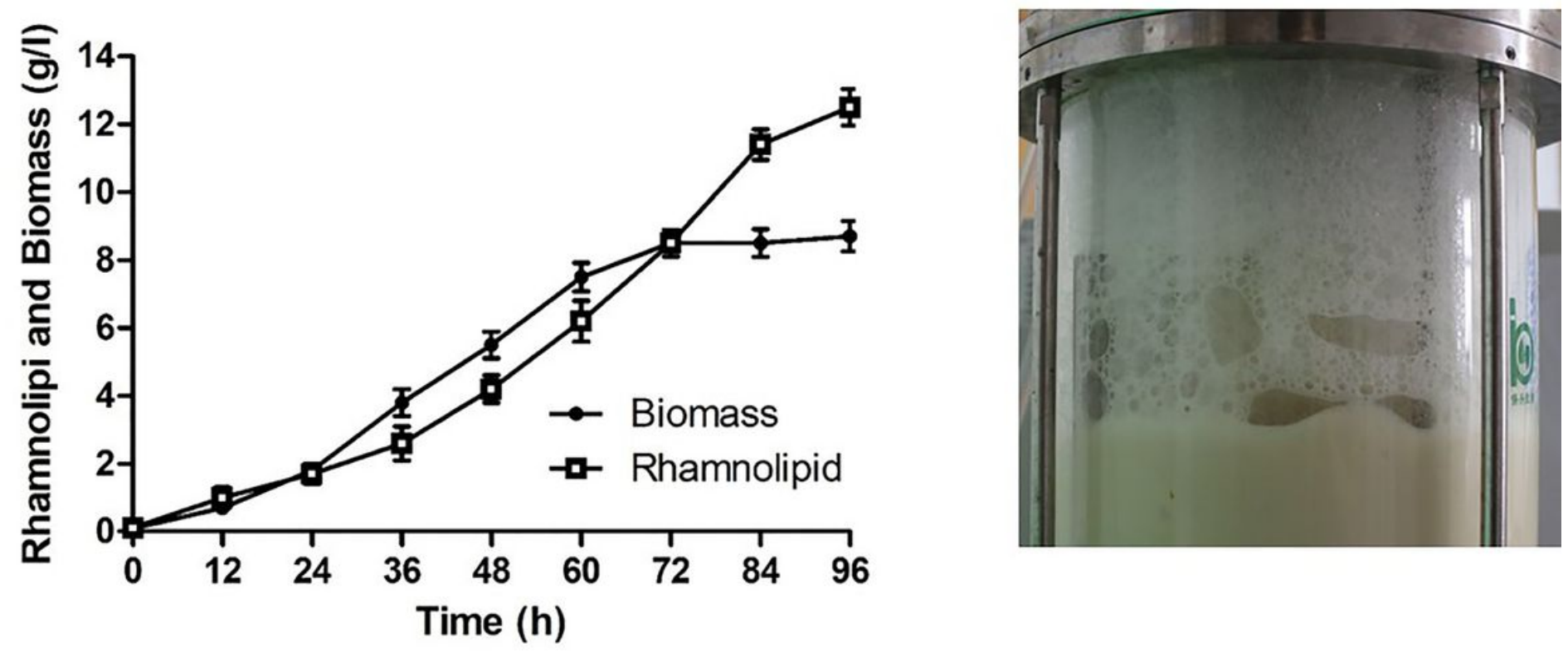

Figure 15

Curves of the production of rhamnolipid and biomass, and digital images by different controlling strategies of $\mathrm{pH}$ in 7.5 I fermenter. (A): the fermentation was controlled at pH5.5; (B): the fermentation was controlled at pH6.0. 
(A)

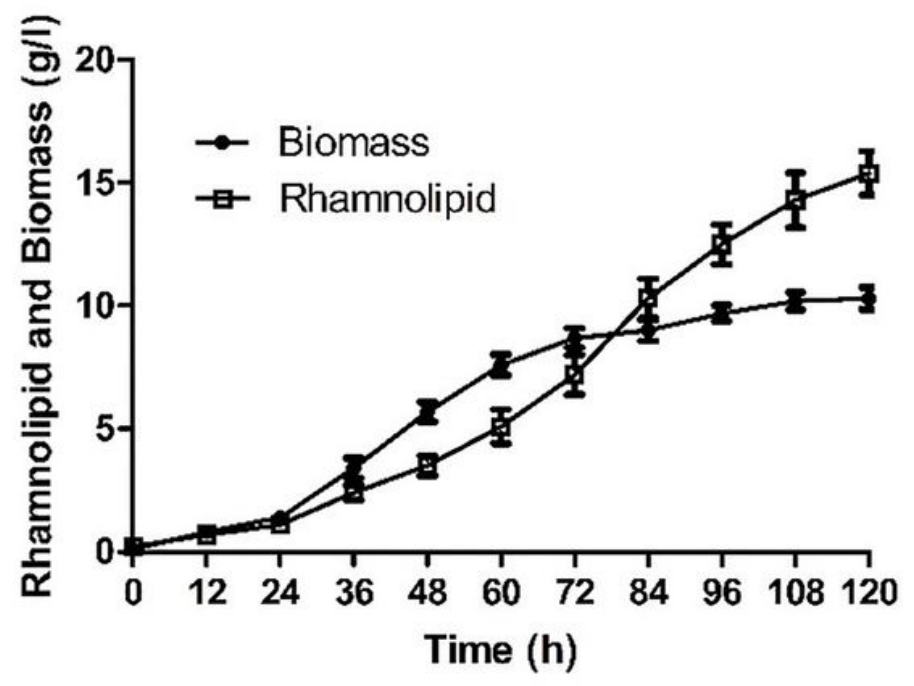

(B)

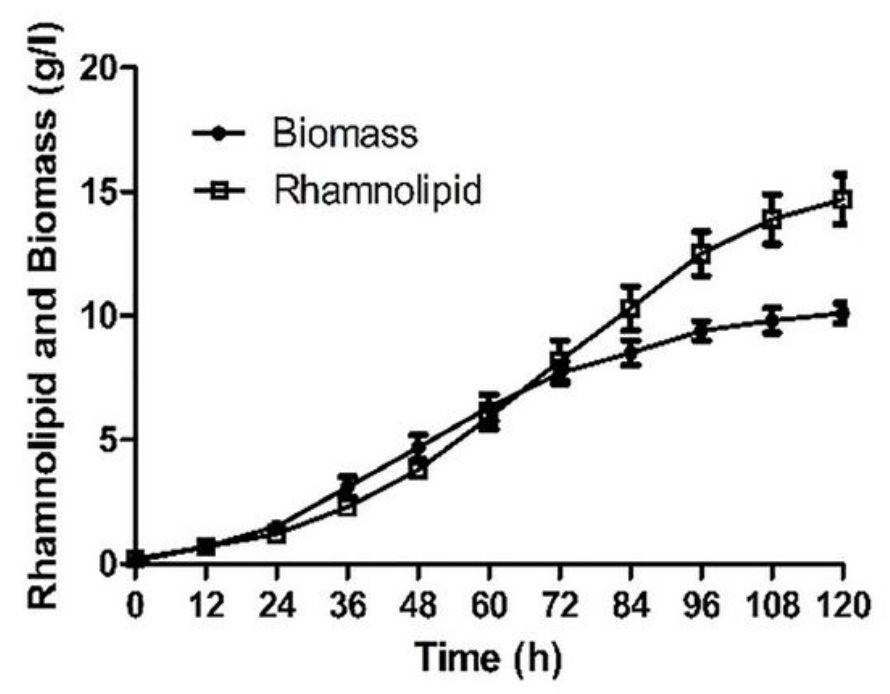

Figure 16

Curves of the production of rhamnolipid and biomass of strain $7(A)$ and strain15 (B) at pH5.5. 
(A)

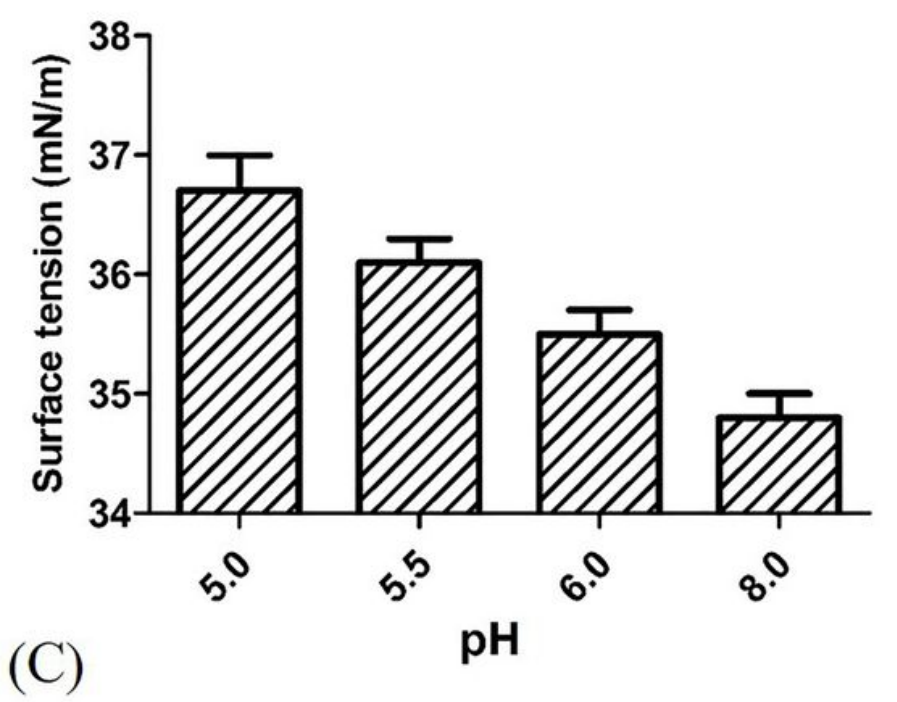

(C)

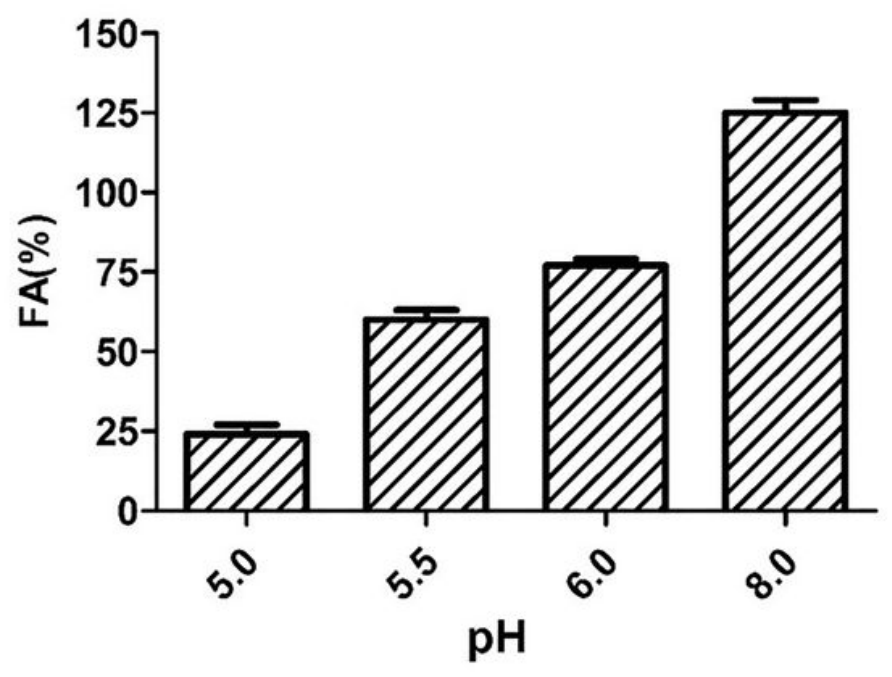

(B)
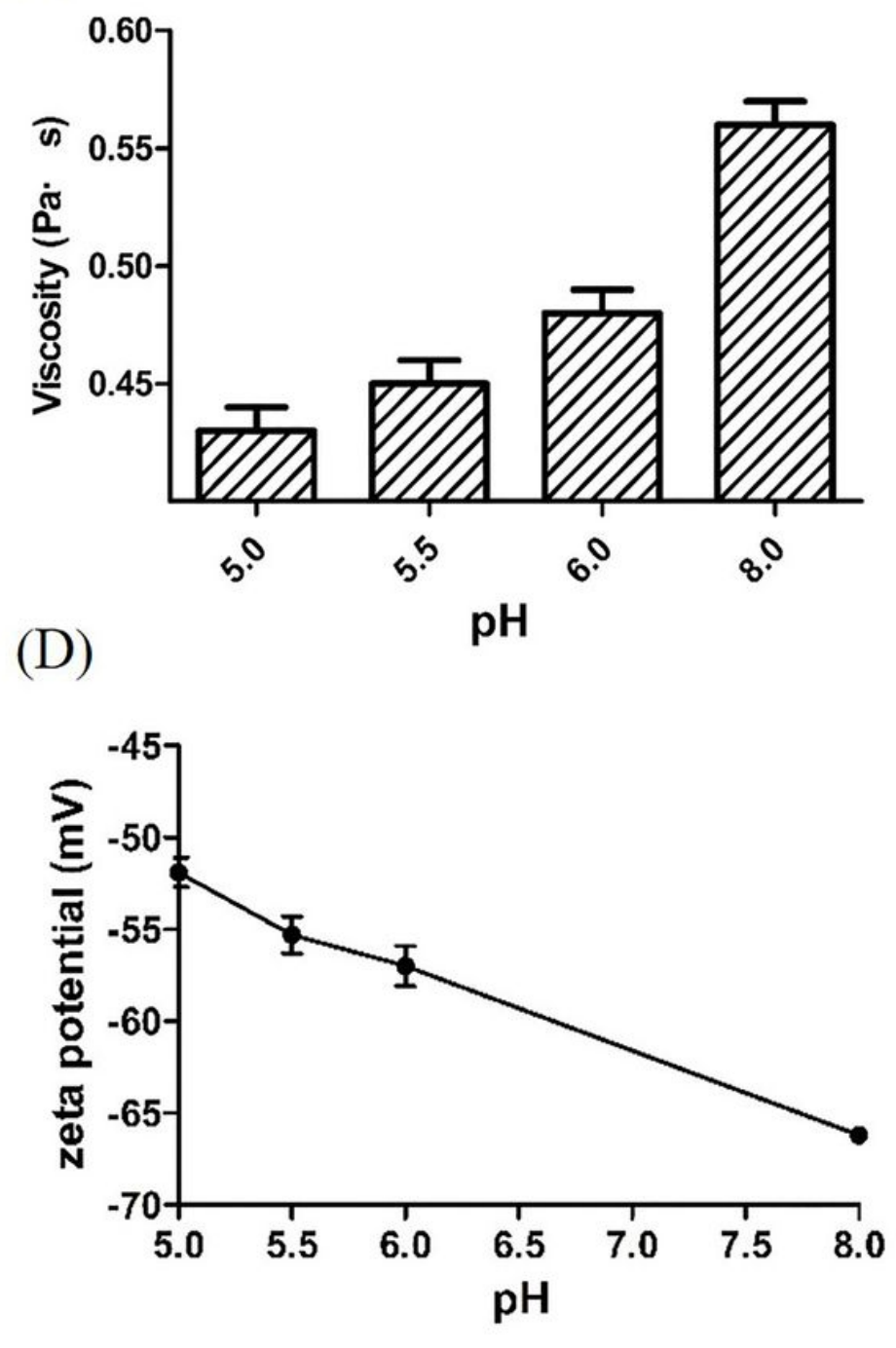

Figure 17

Characterizing the effects of pH5-6 on surface tension (A) and viscosity (B) of fermentation broth of rhamnolipid, and FA (C) and zeta potential (D) of rhamnolipid solution. 

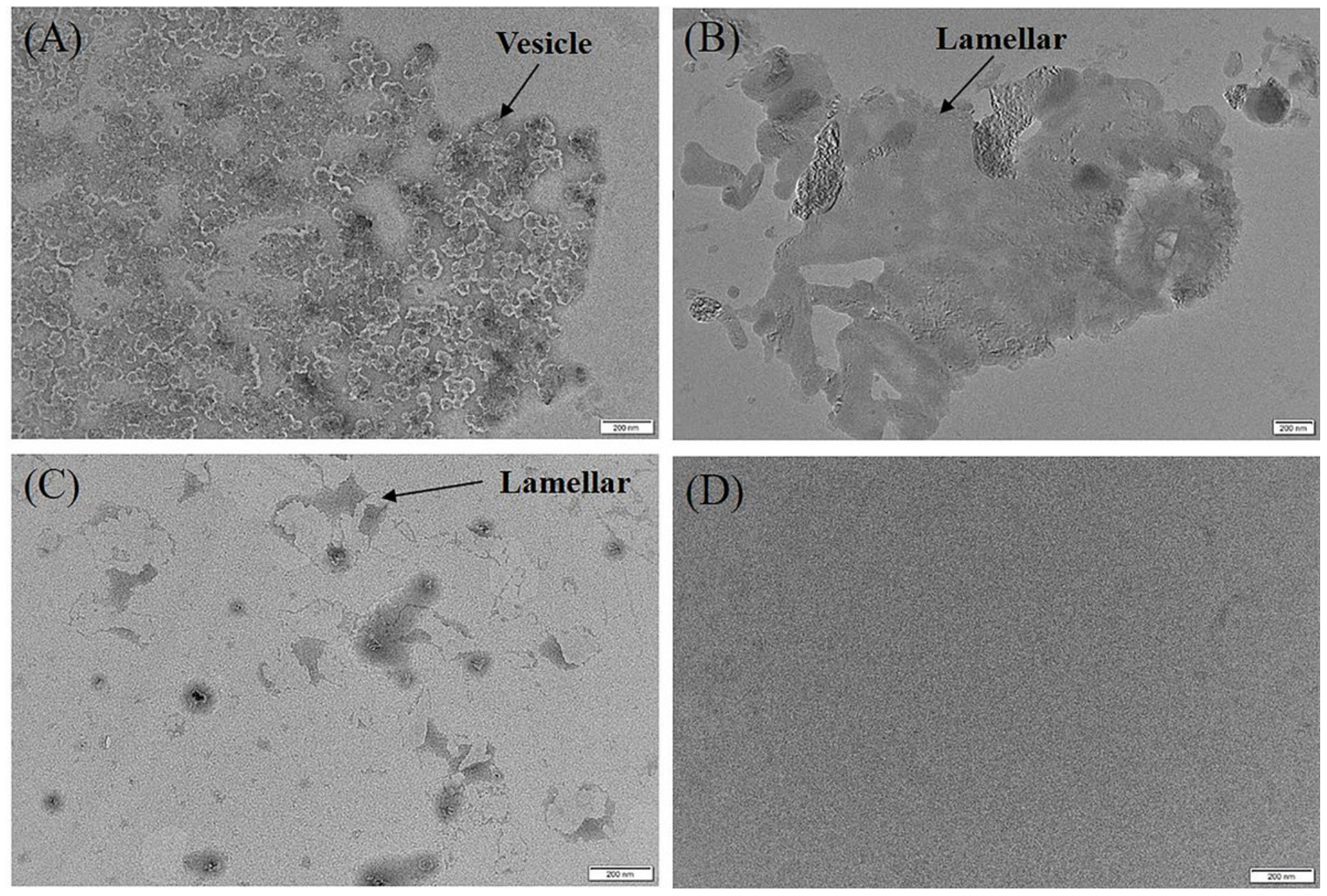

Figure 18

TEM micrographs of the rhamnolipid at pH5-6. A: pH5.0, B: pH5.5, C: pH6.0 and D: pH8.0.

\section{Supplementary Files}

This is a list of supplementary files associated with this preprint. Click to download.

- supplement11.doc

- supplement12.docx 